\title{
MODULATION OF IMMUNITY BY MACROPHAGES
}

\author{
J. Ronald Oehler, ${ }^{1,2}$ Ronald B. Herberman ${ }^{1}$ and Howard T. Holden ${ }^{1}$
}

'Laboratory of Immunodiagnosis, National Cancer Institute, Bethesda, Maryland 20014; ${ }^{2}$ Department of General Surgery, University of Michigan Hospital, Ann Arbor, Michigan 48104, U.S.A.

\section{INTRODUCTION}

The literature concerning the effects of macrophages on the immune response is already large and growing rapidly. Macrophages seem to be involved in almost every phase of the immune response. Not only are they important as effector cells in their own right, but there is now a wealth of information suggesting macrophages may, through a combination of suppressing and enhancing effects, play an important role in regulating the immune response. Evidence obtained both in vivo and in vitro supports the concept of macrophages as immunoregulatory cells. We shall review here the available in vivo and in vitro evidence for augmentation and suppression of immune response by macrophages, and will also suggest how macrophages may play a role as effector cells in $T$ cell suppression and antigenic competition.

Many of the in vitro experiments, on which important conclusions have been based, have compared the results obtained in assay systems using cell populations depleted of macrophages to those obtained using cell populations containing, or highly enriched for, macrophages. Before discussing the details of these experiments, it is important to note that there are problems with interpreting such data.

There is virtually no way to prepare cell populations completely free of macrophages. None of the available methods have been shown to reduce the proportion of macrophages below 0.1 per cent, and this may not be sufficient to rule out the role of very small numbers of macrophages as auxiliary cells for the induction of immune responses. Most of the macrophage depletion procedures are based on adherent or phagocytic properties of macrophages. Petri dish adherence (Mosier, 1967) allows separation of the cells into two populations which can be tested alone or after recombination. The resultant populations, however, are by no means pure and the degree of depletion of macrophages is not as good as that achieved by other techniques. Passage of lymphoid cells over adherence columns of nylon wool (Julius et al., 1973), rayon cotton (Kirchner et al., 1974b), glass beads (Shortman, 1968), or Sephadex G-10 (Ly and Mishell, 1974) allows rather good depletion of adherent cells. However, since B cells are adherent, albeit less than macrophages, those procedures most effective in depleting adherent cells must of necessity deplete a certain proportion of the B cells. In fact, a procedure based on this principle has been described to obtain a purified population of $\mathrm{T}$ cells simply by depleting all of the adherent cells (Julius et al., 1973). Since, however, as many as 80 per cent of the cells are lost when performing such procedures, it is obvious that even some $\mathrm{T}$ cells are depleted. In addition to the separation procedures based on the adherent properties of macrophages, incubation of cells with powdered iron to allow phagocytic cells to ingest the iron particles, and then passage of the cells through a strong magnetic field to obtain a population free of phagocytes (iron and magnet technique), has been a useful technique to obtain a phagocyte-depleted population (Kirchner et al., 1974b). However, since the percentage of the cells recovered (50-60 per cent of normal spleen cells) is routinely lower than the percentage of cells which are non-phagocytic, it is clear that even this depletion technique is not entirely selective for macrophages. Another approach to the problem of obtaining purified cell populations has been the 
use of procedures wherein lymphocytes are allowed to rosette with heterologous erythrocytes and then placed over a Ficoll-Hypaque density gradient which separates the rosette-forming cells ( $\mathrm{T}$ cells) from the non-rosette-forming cells. The use of such procedures has been reported in guinea pigs (Rosenstreich and Oppenheim, 1976) and humans (West et al., 1976). Combinations of adherence depletion techniques and enrichment techniques such as just described seem likely to yield the purest populations. In addition to the above techniques, several substances and compounds have been reported to be selectively toxic for macrophages. Silica and carrageenan (Allison et al., 1966) have been used in vivo and in vitro to deplete macrophage activity. Trypan blue (Hibbs, 1974) has been reported to be similarly effective. Finally, there are several reports of the use of 'specific' anti-macrophage sera and complement to kill macrophages (Feldmann and Palmer, 1971; Gorczynski, 1976). Unlike mouse T cells which express allelic forms of theta and Ly antigen on their surfaces, allelic forms of macrophage surface antigens have not been identified in any species thus far. Therefore, the antisera must be produced in heterologous species and attempts made to render them specific, by extensive absorption procedures with cell populations free of macrophages. However, as is apparent from the above discussion, macrophage-free populations are difficult to prepare, and further, if readily available, they would largely obviate the need for anti-macrophage sera. The difficult problems in this area have been reviewed by Leibovich and Ross (1975).

Preparation of pure macrophage populations is also difficult. In rodents and guinea pigs, a population enriched for macrophages can be obtained by washing out the peritoneal cavity, and many investigators refer to peritoneal exudate cells and macrophages interchangeably. Mice normally have $2-3 \times 10^{6}$ macrophages resident in the peritoneal cavity which can be washed out. It is important to note, however, that the resultant population is heterogeneous, consisting of about 60 per cent lymphocytes, 35 per cent macrophages, and occasional mast and other cells (Edelson and Cohn, 1976). If irritating agents such as light mineral oil, 10 per cent proteose peptone broth, or thioglycolate are placed in the peritoneal cavity, a sterile peritonitis develops. Initially there is an influx of neutrophils, maximally present about $48 \mathrm{hr}$ after injection of the irritant. By 72-96 hr, most of the neutrophils have disappeared and macrophages make up the majority of the cells in the peritoneal exudate (PEC). Shevach (1976) reported that in guinea pigs, 3 days after i.p. injection of light mineral oil, the PEC consisted of 75 per cent macrophages, 10 per cent neutrophils and 15 per cent lymphocytes. By allowing such PEC to adhere to glass slides for $3 \mathrm{hr}$ and washing off the nonadherent cells, a population consisting largely of macrophages and neutrophils remained (Lipsky and Rosenthal, 1973). Neutrophils, unlike macrophages, do not survive overnight incubation in media at $37^{\circ}$ (Edelson and Cohn, 1976). Thus, Lipsky and Rosenthal (1973) reported that after overnight incubation, the adherent PEC remaining on the slides after vigorous washing were 99 per cent pure macrophages. Erb and Feldmann (1975a) used similar adherence techniques to purify PEC from mice. In addition, they treated the adherent PEC with both an anti-T cell and anti-B cell serum and complement followed by irradiation with $200 \mathrm{R}$. They reported that after thorough washing the macrophages were 99.7 per cent pure. Katz and Unanue (1973) used similar procedures in mice, injecting $1 \mathrm{ml}$ of 10 per cent proteose peptone broth to induce the PEC. After 3 days, $8-15 \times 10^{6}$ PEC could be obtained which were 85 per cent pure macrophages. When such mice were irradiated with $660 \mathrm{R} 24 \mathrm{hr}$ prior to harvesting, only $4 \times 10^{6} \mathrm{PEC}$ were recovered but 98 per cent were macrophages. In humans, PEC are obviously not readily available. However, Rode and Gordon (1974) could obtain essentially pure populations of monocytes from human peripheral blood leukocytes (PBL) separated from the red blood cells (RBC) with a Ficoll-Hypaque gradient, by allowing the PBL to adhere to glass Petri dishes for 8 days and vigorously washing off all remaining nonadherent cells. It should be noted that mosi of the procedures used to induce macrophages in the peritoneal cavity, or to isolate the macrophages, cause activation and other functional changes. For example, adherence to a surface results in increased protein synthesis and increased enzyme production by macrophages (Bodel et al., 1977). 
Whatever procedures are used to prepare macrophage-depleted or -enriched cell populations, it is obvious that the purity of the resultant population must be documented. Several methods are available for identification of macrophages and monocytes, but none are entirely satisfactory. The ingestion of various substances such as latex particles, colloidal carbon and heterologous erythrocytes has been used to identify phagocytic cells. In addition, histochemical staining techniques (Goldstein and Blomgren, 1973), particularly for nonspecific esterase (Yam et al., 1971), are now widely used to identify macrophages. However, it is possible that even these methods may be fallible. Nathan et al. (1976) have expressed concern that a population of cells that they have isolated from the peritoneal exudates of mice pretreated with Bacille Calmette-Guerin (BCG) which have strong anti-proliferative effects on tumor cells in vitro, although adherent and staining positive for esterase, may be non- or poorly phagocytic under the conditions they used. They have been reluctant to call these cells macrophages and thus raise the question of whether cells other than macrophages and monocytes may stain positive for nonspecific esterase. Confirmatory reports of a discrete population of esterase positive, non-phagocytic cells, however, have not yet appeared. Enumeration of macrophages by any of the procedures is complicated by the fact that in any cell population there are not only mature macrophages and monocytes but also macrophage and monocyte precursors which may not be readily identifiable. These cells, although less adherent (Cline and Sumner, 1972), much less susceptible to anti-macrophage sera and complement (Virolainen et al., 1972), and probably non-phagocytic, can mature during in vitro culture and function as macrophages even after the most efficient depletion procedures based on these functional properties. Many of these problems have been extensively discussed in a recent book (Bloom and David, 1976).

Macrophages appear to be a heterogeneous group of cells, both functionally and morphologically. At the present time it is not clear whether the heterogeneity is simply a result of different levels of maturation or whether there are in fact distinct subpopulations of macrophages which can be identified on the basis of certain cell surface or functional characteristics. During maturation from promonocyte through monocyte and immature macrophage to mature macrophage, there are many changes in their functional characteristics. Territo and Cline (1976) have provided evidence that the frequency of cell division decreases as the cells mature, while other characteristics such as phagocytic activity, glass adherence, microbicidal activity, surface receptors for immunoglobulin and the ability to interact with lymphoid cells in various immune reactions, generally increase.

Macrophages or monocytes from different sources display divergent characteristics. Bennet (1966) has shown that when macrophages from different tissue sources were isolated and cultured in vitro, their rate of attachment to glass as well as their mitotic rate in culture varied. Based on these features, Bennet described three categories of macrophages: peritoneal and peripheral blood macrophages that attached rapidly and had a low mitotic rate; bone marrow, spleen and liver macrophages that spread slowly and had a high mitotic rate; and alveolar macrophages that spread rapidly and had a high mitotic rate. Nitulescu and Förster (1976) reported that there were antigenic differences between the alveolar and peritoneal macrophages in rats. Walker (1967a) has also discussed the differences in functional activity between macrophages from various sources. He noted that peritoneal macrophages had a higher bactericidal activity than did alveolar macrophages and in addition that they had higher $\mathrm{Fc}$ receptor avidity. Furthermore, peritoneal macrophages responded well to chemotactic agents and were very efficient at rendering antigen immunogenic, while alveolar macrophages had low activity in these tests. Similarly, Boumsell and Meltzer (1976) have noted differences in the chemotactic response of blood monocytes and peritoneal macrophages to lymphocyte and complement-derived chemotactic substances with regard to both time-course and dose response. Hence, there is evidence that macrophages from different tissues may vary considerably in their functional characteristics. Whether this is due to stage of maturation or to subpopulation distribution is not clear. 
Macrophages from a single tissue source may also be heterogeneous in terms of their surface characteristics and their functional reactivity. Rhodes (1975) found that there was marked variability in the avidity of the $\mathrm{Fc}$ receptors among guinea pig peritoneal macrophages. If the macrophages were induced with an inflammatory agent, there was a six-fold increase in the proportion of macrophages with high avidity $\mathrm{Fc}$ receptors. Heterogeneity in macrophage function has been noted by a number of investigators and has recently been reviewed by Walker (1976a). Basically, two types of observations suggested there may be functional subclasses of macrophages: (i) only a certain percentage of macrophages performed certain functions under similar conditions (such as phagocytosis of bacteria or erythrocytes), or (ii) macrophage populations which were fractionated based on their density or size, could be identified on the basis of various functional characteristics. Walker (1976b) used a discontinuous Ficoll gradient to fractionate rabbit peritoneal exudate cells into five subpopulations. Several different functional tests were then performed with the cells from each fraction. He found that binding of ${ }^{125} \mathrm{I}-\mathrm{T} 2$ antigen was greatest in fraction 1 (least dense) while binding through the $F_{c}$ receptor was greatest in the denser fractions 3 and 4 . In addition, Walker fractionated rat peritoneal exudate cells from animals that had been immunized with a chemically induced tumor (plus BCG) and found that the cytotoxic reactivity of the macrophages resided predominately in two fractions. Similarly, differences in the size of macrophage effector cells were noted by Holden et al. (1976) in studies of the growth inhibitory activity of macrophages isolated from murine sarcoma virus-induced tumors. There were two functional subpopulations with different cell sizes (as determined by sedimentation velocity at $1 \mathrm{~g})$.

All of these studies, however, are complicated by the fact that different methods of induction were used for harvesting macrophages and the cells may exhibit various levels of activation. In addition, the process of activation may call in a specific subpopulation of cells or, as suggested recently by Bomford and Olivotto (1975) and Woodruff et al. (1975), the activation process may cause macrophage precursors to differentiate into mature cells. Unfortunately at this time there is not enough information on subpopulations of macrophages from any one source to determine whether different functions will regularly be associated with particular macrophage subpopulations.

In all, it is apparent that dogmatic statements concerning the absolute requirement for macrophages, or the lack thereof for various immune responses, require careful documentation to be at all convincing. However, despite the above problems, it has still been possible to extensively study the role of macrophages in enhancing and suppressing immune responses, and evidence has been presented that macrophages play a vital role in regulating the immune response.

\section{ENHANCEMENT OF THE IMMUNE RESPONSE BY MACROPHAGES}

Macrophages have been shown to enhance almost every phase of the immune response. For many immune responses generated in vitro, there appears to be an absolute requirement for macrophages. This, of course, does not prove that macrophages are required in vivo or, if they are required, that they perform the same function in vivo as they do in vitro. When lymphocytes are cultured without macrophages, the viability after 4-5 days under some conditions is lower than when macrophages are present (Chen and Hirsch, 1972; Bevan et al., 1974). In contrast, there is little or no evidence that macrophages enhance the viability of lymphocytes in vivo. Thus, it would seem that enhancing effects of macrophages on the immune response in vitro, which result only from the improvement of lymphocyte viability, may have limited relevance in vivo. One way to prevent such problems would be to perform in vitro investigations under optimal tissue culture conditions which are not substantially improved by the addition of macrophages. In vivo experiments on the 
role of macrophages in enhancing immune responses also have problems. Observations made in vivo occasionally raise as many questions as they answer. Subclinical infections or fluctuations of hormone levels may affect in vivo experiments in ways that would be difficult to predict. However, with a combination of in vivo observations, and in vitro experiments designed to dissect and explain the results obtained in vivo, meaningful interpretations may be suggested. In this section we shall discuss the evidence that macrophages can enhance immune response in vivo and then we shall discuss the evidence obtained in vitro as possible explanations for the in vivo findings. Recent concepts regarding the mechanisms of the enhancing effects of macrophages, including some of the current concepts of antigen presentation, will be reviewed.

\subsection{Enhancement of the Immune Response In Vivo}

There is considerable evidence that macrophages can enhance the immune response in vivo (Mitchison, 1969; Klaus, 1974; for reviews see Unanue, 1972; Oppenheim and Seeger, 1976). This is supported by many experiments in which injection of soluble protein antigen bound to macrophages (by exposure to live macrophages in vitro or in vivo) has resulted in stronger immune responses in experimental animals than has injection of equivalent quantities of free soluble antigen. In addition, there is evidence that certain immunodeficient states are a result of an incompetent reticuloendothelial system (Carter and Rector, 1972; Hardy et al., 1973; Blaese, 1975).

Both humoral and cellular responses have been shown to be enhanced by injection of antigens bound to macrophages (Unanue, 1972; Oppenheim and Seeger, 1976). Routinely, macrophages have been washed after exposure to radiolabeled soluble antigen and then injected into the host. The amount of antigen injected with the macrophages has been determined by the radioactivity of the injected cells. With some exceptions (to be discussed below), the response was ten- to a thousand-fold higher on a per microgram basis when the antigen was injected bound to macrophages (Mitchison, 1969; Klaus, 1974). Other cells such as fibroblasts can bind approximately the same amount of soluble antigen as macrophages, but there is general agreement that antigens injected bound to fibroblasts fail to augment strong immune responses (Mitchison, 1969; Klaus, 1974). As has been found with other macrophage functions, the ability to enhance immunogenicity is radioresistant (Unanue, 1972). However, viable macrophages are required. Mitchison (1969) has shown that antigen transferred on dead macrophages was no more immunogenic than antigen injected alone. Also, the ability of the transferred cells to interact with host cells is required. Macrophages in Millipore chambers implanted into the peritoneal cavities of mice did not enhance immunogenicity (reviewed by Unanue, 1972).

Although many soluble antigens are more immunogenic when transferred bound to macrophages, some are as immunogenic when injected alone. The ability of macrophage-bound antigen to enhance immunogenicity has been shown to be inversely related to the ability of macrophages to clear the antigen from the serum in vivo (reviewed by Unanue, 1972). Keyhole limpet hemocyanin (KLH) was taken up very well by macrophages in vivo. Preincubation with macrophages in vitro did not enhance the response to it (Unanue, 1969). Presumably when such antigens are inoculated in soluble form, they are rapidly bound to tissue macrophages and are thus presented to the immune system in the same form as when they are bound to macrophages in vitro. On the other hand, human serum albumin (HSA) was phagocytized poorly by murine macrophages in vivo, and preincubation of HSA with macrophages in vitro increased the resultant antibody response about one thousand fold when compared to equal microgram quantities of free HSA (Mitchison, 1969). In contrast to free soluble antigen, macrophage-bound antigen has not been shown to induce tolerance (Unanue, 1972).

In addition to enhancement of a humoral or cellular immune response to antigen, macrophages can influence the type of response elicited. In guinea pigs, Oppenheim 
and Seeger (1976) have shown that small doses of tetanus toxoid $(0.1 \mu \mathrm{g})$, when bound to macrophages and given either intradermally or intracardiacly, induced delayed hypersensitivity type responses to subsequent challenge. In contrast, soluble antigen given in the same dose, schedule and routes resulted in immediate Arthus reactions, indicating high levels of circulating antibody. Further, two sequential injections of macrophage-bound tetanus toxoid resulted only in stronger delayed hypersenstivity. Boosting with tetanus toxoid alone, on the other hand, resulted in high levels of circulating antibody 2 weeks later (Oppenheim and Seeger, 1976). Thus, in some systems the use of macrophage-bound antigen for immunization results not only in an enhanced response but also in a response qualitatively different from that obtained with free soluble antigen.

Finally, many of the immunodeficiencies of newborn animals appear to be associated with the immaturity of the mononuclear phagocytes. Neonatal mice responded very poorly to sheep erythrocytes when compared to adult animals (Argyris, 1968). However, the antibody response could be augmented considerably if the newborn mice were reconstituted with adult peritoneal exudate cells 2 days before immunization. Since mouse spleen cells have been shown to contain antigen sensitive cells $24 \mathrm{hr}$ after birth (Carter and Rector, 1972), the deficiency in neonatal mice would not appear to be in this population of cells. Furthermore, adoptive transfer studies of neonatal and adult mouse spleen cells into $\mathrm{X}$-irradiated recipients also suggested that newborns lacked cells needed to process the antigen, and that these cells were radioresistant, indicating that they might be macrophages (Carter and Rector, 1972). Hardy et al. (1973) found that the antibody response in mice to sheep erythrocytes as well as to Shigella paradysentheria was not evident until 3-5 days after birth. In exploring the role of the macrophage, they found the PEC from neonatal mice preincubated with Shigella antigen were unable to induce an antibody response in adult mice; while the use of PEC from adult mice led to significantly higher titers of antibody in the recipients. From this they concluded that the macrophages from newborn mice were incapable of taking up and processing the Shigella antigen sufficiently to induce a detectable antibody response. Blaese (1975) performed studies on the antibody response to several antigens in newborn rats and found that the response of the animal depended on the type of antigen used for immunization. Rats $18 \mathrm{hr}$ old did not respond to sheep or burro erythrocytes, KLH or type III pneumococcal polysaccharide, but responded fairly well to killed Brucella abortus. If the sheep erythrocytes given to the neonate were mixed with unfractionated PEC or macrophage-enriched PEC from adults, there was a strong antibody response. Antibody responses to KLH or burro erythrocytes could be induced in neonates in a similar fashion. It is of interest that Brucella as well as several other macrophage activators, when injected into newborn rats with the immunogen, were able to substitute for adult macrophages, presumably by activating the resident macrophages. Finally, by inoculating neonates with high doses of antigen it was relatively easy to induce tolerance to that antigen. Blaese (1975) suggested that this was also due to the immaturity of the macrophages in these animals, since the rats did not become tolerant when antigen was injected with adult macrophages.

\subsection{Enhancement of the Immune Response In Vitro}

In vivo experiments such as those described above have shown that macrophages could enhance and, in some cases, qualitatively alter the expression of the immune response. Although demonstrating the significance of macrophages in eliciting various immune responses, such in vivo experiments do not allow definition of the mechanisms of action. Unlike experimental models of $T$ cell or $B$ cell deficient animals (e.g. the nude mouse or bursectomized chicken), no model of complete and selective macrophage deficiency is readily available. Macrophages are functionally radioresistant so even in adoptive transfer experiments, resident macrophages may participate in the immune response. Agents which are considered to be selectively 
toxic for macrophages such as carrageenan, silica (Allison et al., 1966), or trypan blue (Hibbs, 1974) are less than totally effective (Sawicki and Catanzaro, 1975). In addition, in in vivo experiments, it is usually difficult to identify the phase in the immune response during which macrophages are required. For example, in the study of Schwartz and Leskowitz (1969), in which simultaneous injection of carrageenan with antigen temporarily suppressed delayed hypersensitivity responses in guinea pigs, one cannot distinguish between the effect of carrageenan on macrophages involved in the afferent or the efferent limb of the response. In contrast, in vitro experiments allow more precise dissection of the site of action of macrophages.

\subsubsection{The Macrophage Requirement for the Generation of Antibody-Producing Cells} In Vitro

There are several techniques for generating antibody responses in a totally in vitro environment. One of the most commonly used techniques is the Mishell-Dutton culture system (Mishell and Dutton, 1966), followed by a Jerne plaque assay (Jerne and Nordin, 1963). Mosier (1967), using a modification of such a system, was one of the first investigators to show a requirement for two distinct cell types for the in vitro primary generation of antibody-forming cells (AFC) in response to sheep erythrocytes (SRBC). After separating murine spleen cells on the basis of adherence to a glass Petri dish, neither the nonadherent nor the adherent fraction could generate antibodyforming cells. However, the recombined fractions responded as well as the unfractionated population. These results have been verified with antibody production to all heterologous RBC tested (Katz and Benacerraf, 1972; Pierce, 1969, 1973; Feldmann and Palmer, 1971; Sjobert et al., 1972; Shortman and Palmer, 1971; Shortman et al., 1970; Cosenza et al., 1971; Mosier, 1968; McIntyre and Pierce, 1973), In addition, the macrophage requirement for $\mathrm{AFC}$ production has been demonstrated using hapten-protein conjugates (Feldmann et al., 1974) or synthetic soluble copolymers (Pierce et al., 1974; Kapp et al., 1973) as antigens. IgM, IgG and IgA plaque-forming responses have all been shown to require macrophages in vitro (Pierce, 1973). Although early reports suggested that the secondary response was not dependent upon macrophages (Pierce, 1969; Katz and Unanue, 1973), it has now been shown that both primary and secondary responses require adherent and phagocytic cells (reviewed by Oppenheim and Rosenstreich, 1976). Whether other cells without known immunologic effects can substitute for macrophages in these in vitro responses is not entirely clear. Katz and Unanue (1973) have reported that DNP-KLH bound to fibroblasts could induce an AFC response comparable to that induced with DNPKLH bound to macrophages when added to nonadherent DNP-KLH-primed mouse spleen cells in a Mishell-Dutton culture system. Similarly, Möller et al. (1976) have recently shown that fibroblasts could reconstitute the primary AFC response of nonadherent mouse spleen cells in a Mishell-Dutton culture system with SRBC. In these cases, however, it is likely that residual macrophages left in the spleen preparations after the macrophage-depletion procedures were responsible for inducing the responses observed and that the fibroblasts simply amplified the response by improving the culture conditions by a nonspecific feeder effect. Be that as it may, in addition to adherent cells and $B$ cells, $T$ cells are required for the generation of AFC to the above antigens in vitro. In contrast, another class of antigens which can stimulate AFC in vitro in the absence of T cells (T-independent antigens) have until recently been considered macrophage independent (Feldmann et al., 1974; Mosier et al., 1974; Feldmann, 1972a; Lemke et al., 1975). These findings suggested that the primary role of macrophages in enhancing AFC production to T-dependent antigens might be related to the requirement for $\mathrm{T}$ cells. However, recent reports (Chused et al., 1976; Lee et al., 1976; Pike and Nossal, 1976), showing that some T-independent antigens do in fact require macrophages, do not support this notion. Polyclonal antibody responses to B cell mitogens such as LPS (Lemke et al., 1975) which are also $\mathrm{T}$-independent, have not (with one exception) been shown to require macrophages in 
vitro (Oppenheim and Rosenstreich, 1976; Rosenstreich and Oppenheim, 1976). The exception is a report by Kragnoff et al. (1974) which showed that the LPS-induced proliferative response of $\mathrm{B}$ cells from the Peyer's patches of nude mice required either 2-mercaptoethanol or macrophages. However, in this case, $T$ cells were also required, suggesting this situation was unusual if not unique.

\subsubsection{The Requirement for Macrophages for T Cell Responses In Vitro}

Consistent with the enhanced immunogenicity afforded by macrophage-bound antigen in induction of delayed hypersensitivity responses in vivo (Oppenheim and Seeger, 1976) are experiments showing that macrophages are required for the generation of $\mathrm{T}$ cell responses in vitro. $\mathrm{T}$ cell proliferative responses in mixed leukocyte culture (MLC) were found to require macrophages in mice (Bevan et al., 1974) and humans (Jones, 1971). Similarly, the in vitro generation of cytotoxic effector cells to alloantigens in MLC systems [cell-mediated lympholysis (CML)] has been shown to require macrophages in mice (Wagner et al., 1972). However, whether macrophages function to enhance the immunogenicity of alloantigens is unclear. An alternative explanation for the requirement for macrophages in MLC is that the primary stimulating cell in the MLC is the allogeneic macrophage. This has been observed with MLC in guinea pigs (Greineder and Rosenthal, 1975b), humans (Rode and Gordon, 1974) and rats (Oehler and Herberman, 1977). In these studies, syngeneic macrophages did not reconstitute the MLC responses abrogated by depletion of macrophanges from both stimulating and responding populations.

$T$ cell proliferative responses to nonspecific mitogens have also been shown to require macrophages. Rosenstreich and Oppenheim (1976) have recently reviewed evidence that $\mathrm{T}$ cell proliferative responses to Concanavalin $\mathrm{A}$ (Con $\mathrm{A}$ ) and phytohemagglutinin (PHA) in guinea pigs are macrophage dependent. Nonadherent human peripheral blood mononuclear leukocytes (PBL), purified by passage over a column containing glass beads, have a diminished proliferative response to PHA which could be reconstituted with as few as 1 per cent phagocytic cells (Oppenheim et al., 1968). Both Oppenheim et al. (1968) and Lohrmann et al. (1974) have shown that the dependence of human lymphocytes on monocytes for strong proliferative responses to PHA is much easier to demonstrate when suboptimal concentrations of PHA are used. Our laboratory has recently separated human PBL on the basis of adherence by passage of the cells through Sephadex G-10 columns (Jerrells, Dean and Herberman, unpublished observations) and determined the reactivity to PHA and Con A. We found that populations depleted of adherent cells, with less than 1 per cent esterase positive cells, were essentially unresponsive to Con A, whereas the responses to PHA were diminished less consistently, if at all. Reconstitution of the nonadherent cells with irradiated adherent autologous cells which were enriched for esterase positive cells (monocytes) resulted in enhanced PHA and Con A responses, equal to or even greater than the response of ule original untreated population. Similarly, in other experiments, we have observed that human PBL forming rosettes with SRBC (ERFC), when separated from non-rosetting cells by centrifugation in a Ficoll-Hypaque density gradient, may proliferate little if at all in response to Con A (Dean et al., 1977; West, Dean and Herberman, unpublished observations). As observed with the adherent cell-depleted populations described above, the PHA response was diminished less than the Con A response. Approximately 1 per cent of the cells prepared in this way stained positive for esterase or ingested latex particles, and essentially none of the cells had detectable surface IgM. When such populations were further depleted of cells bearing an $\mathrm{Fc}$ receptor by adherence to monolayers of antibody-coated SRBC attached to Petri dishes with poly-l-lysine (West et al., 1977), the nonadherent population (consisting of cells lacking the $\mathrm{Fc}_{\mathrm{c}}$ receptor and esterase) also failed to respond to PHA. When reconstituted with various concentrations of adherent autologous PBL, the response to both mitogens was restored. These observations suggest that human PBL require adherent cells, presumably macrophages, to proli- 
ferate in response to Con A and that fewer such cells, or a particular subpopulation of adherent cells bearing an Fc receptor, are needed for responses to PHA. Blaese et al. (1977), in studies with human PBL, have provided evidence that different macrophage-dependent in vitro responses may have varying requirements for macrophages. By using a series of macrophage depletion techniques, they could show a hierarchy of macrophage dependence for several in vitro responses. Monocyte-mediated antibodydependent cell-mediated cytotoxicity (MMADCC) was the assay system most dependent on macrophages. Since macrophages are the effector cells in this assay, even minimal decreases in the percentage of macrophages were associated with decreased cytotoxicity. As more efficient macrophage depletion techniques were used, the synthesis of immunoglobulin induced by pokeweed mitogen (PWM) was depressed. Only the most efficient means of macrophage depletion caused depression of the proliferative response to soluble antigens (Candida and SK-SD). Although less dependent on macrophages than MMADCC and the PWM response, the proliferative response to soluble antigens was still shown to be macrophage-dependent. In contrast to our findings, these investigators could not demonstrate a macrophage requirement for a proliferative response to PHA even by using a Shortman column (Shortman, 1968), their most effective technique, to deplete the adherent cells. All of these data indicate that the proliferative response of human PBL to optimal concentrations of PHA requires very few macrophages indeed.

$T$ cell proliferation in response to the immunological adjuvant Bacillus CalmetteGuérin (BCG) in vitro requires the presence of macrophages (Mokyr and Mitchell, 1975). Mouse thymus cell suspensions, which contain approximately 0.25 per cent macrophages, responded vigorously to $\mathrm{BCG}$, incorporating ${ }^{3} \mathrm{H}$-thymidine $25-35$-fold more than unstimulated controls. When macrophages were depleted to $<0.25$ per cent (undetectable by Giemsa stain), the response to BCG was abolished. There was no diminution of the response to Con $A$, indicating viability of the nonadherent thymus cells, and reconstitution of macrophages to 0.5 per cent completely restored the response to BCG. Reduction of macrophages in the spleen from 10 to 0.5 per cent caused no change in two experiments, but significant augmentation of ${ }^{3} \mathrm{H}$-thymidine incorporation in response to BCG in two others (Mokyr and Mitchell, 1975). Thus, a critical concentration of macrophages $0.25-0.5$ per cent was required for the mitogenic effects of BCG on T cells, with higher concentrations tending to cause diminished reactivity of lymphocytes.

$\mathrm{T}$ cell proliferative responses induced by sodium periodate or neuraminidasegalactose oxidase (NG) require macrophages in guinea pigs (Greineder and Rosenthal, 1975a). In this system, treatment of either macrophages or $T$ cells alone with these materials resulted in strong proliferative responses when the cells were recombined. In contrast, purified lymphocytes treated with periodate or NG and also pretreated with mitomycin $C$ to prevent their own proliferation could not induce a $T$ cell proliferative response when added to unfractionated guinea pig lymph node cells. These observations further confirm the requirement for interaction between $T$ cells and macrophages in the generation of proliferative responses to nonspecific stimuli.

Proliferative responses of primed $\mathrm{T}$ cells to soluble protein antigens have been shown to require macrophages in several systems. In guinea pigs immunized with ovalbumin (OVA) in complete Freund's adjuvant (CFA), lymph node cells depleted of adherent cells did not proliferate in response to the antigens unless reconstituted with adherent cells (Seeger and Oppenheim, 1970; Walderon et al., 1973; Rosenthal and Shevach, 1973; Paul et al., 1976). In addition, purified macrophages, but not lymphocytes preincubated with purified protein derivative of tuberculin (PPD) or OVA and added to purified lymph node cells from immunized animals, induced strong proliferative responses in vitro (Rosenthal and Shevach, 1973; Paul et al., 1976). Similarly, Cline and Swett (1968) have shown that when human PBL from tuberculinsensitive donors were depleted of adherent cells, no blastogenic response was observed in the presence of PPD. Addition of adherent cells with the characteristics of monocytes to the cultures of purified PBL and PPD resulted in strong proliferative 
responses. Viable monocytes were required and separation of the responding lymphocytes from the monocytes with cell-impermeable Millipore membranes prevented the enhancing effect. Similar findings using human PBL have been reported by Blaese et al. (1972).

Primary $T$ cell proliferative responses to soluble protein antigen in vitro have been difficult to demonstrate. However, recently antigen-pulsed macrophages were used to prime purified guinea pig LNC in vitro for subsequent proliferative responses upon re-exposure to antigen-pulsed macrophages (Thomas and Shevach, 1976). As will be discussed, these types of experiments have allowed a more detailed understanding of the macrophage-lymphocyte interaction than was previously possible in experiments where $\mathrm{T}$ cells were primed in vivo.

2.2.2.1. The requirement for macrophages for the production of lymphokines in vitro. In addition to the induction of $T$ cell division, antigens and mitogens induce the production by $\mathrm{T}$ cells of numerous mediators termed lymphokines. In vitro systems have been developed to investigate the events leading to lymphokine production. Thus far, all such in vitro systems show that macrophages are required for the production of mediators by $\mathrm{T}$ cells.

Migration inhibition factor (MIF) production by guinea pig lymphocytes primed with CFA required macrophages pulsed with PPD (Ohishi and Onoue, 1975). In this case, the macrophage requirement could be replaced by supernatants of macrophages stimulated with lipopolysaccharide (LPS) (Ohishi and Onoue, 1976). Similarly, our laboratory (Landolfo et al., 1978) has recently shown that spleen cells from C57BL/6 mice bearing Moloney sarcoma virus-induced tumors could be induced to produce $\mathrm{MIF}$ by culture with $3 \mathrm{M} \mathrm{KCl}$ extracts of tumor cells bearing relevant antigens. Spleen cells depleted of macrophages by adherence techniques did not produce MIF when cultured with the $3 \mathrm{M} \mathrm{KCl}$ extract. However, when purified macrophages from light mineral oil-induced peritoneal exudates of normal syngeneic mice were added to the adherent cell-depleted spleen cells in the presence of free antigen, MIF production could again be demonstrated. Further, spleen cells with macrophages which were preincubated with soluble tumor antigens for 2-6 hr and washed to remove all unbound antigen could also produce MIF. More recently, we have shown that only antigen-pulsed spleen cells containing macrophages compatible with the responding cells at the major histocompatibility complex (MHC) could produce MIF (Landolfo et al., 1977). Unlike the findings of Ohishi and Onoue described above for the PPD system in guinea pigs, the macrophage requirement in the MSV tumor system has been shown to require cell-cell contact and could not be replaced by supernatants of LPS-stimulated macrophages (Landolfo, Holden and Herberman, unpublished observations).

In addition to MIF, a number of other mediators are produced by stimulated $\mathrm{T}$ cells in vitro. Macrophages were required for interferon production by PBL from tuberculin-sensitive human donors in response to PPD in vitro (Epstein et al., 1971a). Unprimed human lymphocytes stimulated with PHA produced interferon only in the presence of macrophages (Epstein et al., 1971b). Osteoclast-activating factor (OAF) produced by human PBL in response to PHA required adherent cells (Horton et al., 1974). In guinea pigs, $T$ cell production of macrophage chemotactic factor by primed $\mathrm{T}$ cells stimulated with soluble antigen required macrophages (Wahl et al., 1975). In sensitized humans, the production of fibroblast chemotactic factor in vitro by PBL stimulated with the sensitizing antigen required the presence of adherent cells (Postlethwaite et al., 1976).

In summary, all immune responses involving triggering of $T$ cells, whether to help $B$ cells respond to $\mathrm{T}$-dependent antigens, to help other $\mathrm{T}$ cells to become effector cells, or to mediate effector functions themselves, require at least small numbers of macrophages. In our discussion we have made no effort thus far to distinguish between those macrophage requirements dependent on cellular contact with $T$ cells and the ability of macrophage products to effectively replace the actual adherent cell. 
Similarly, for most of the systems discussed, we have made no distinction between those $T$ cell responses shown to require macrophages which share some region in the MHC and those in which no genetic restriction has been described. Oppenheim and Rosenstreich (1976) have recently reviewed these issues and have presented evidence suggesting that $T$ cell responses to nonspecific mitogens and cellular antigens, i.e., to alloantigens in MLC or CML or heterologous erythrocyte antigens such as SRBC, do not require the presence of intact and viable macrophages in the culture, but instead only require soluble factors from macrophages such as lymphocyte-activating factor (LAF) (Gery et al., 1972). These factors act, with the cellular antigens or mitogens, as 'second signals' analogous to second signals required for B cell activation to promote $T$ cell triggering and to amplify the response (Rosenstreich and Oppenheim, 1976). Several lines of evidence account for these views. Antibody production to heterologous erythrocytes in vitro required $\mathrm{T}$ cells and macrophages as well as $\mathrm{B}$ cells as previously described. However, Calkins and Golub (1972) have shown that macrophages could provide the helper effect even when separated from macrophagedepleted spleen cells by a cell-impermeable Millipore filter. The antigen (SRBC in this case) and not the macrophages had to be in contact with the responding cells. Further, Chen and Hirsch (1972; and reviewed by Chen and Hirch, 1975) have shown that the requirement for macrophages in a Mishell-Dutton culture system could be replaced entirely with various thiols, of which the most widely used is 2-mercaptoethanol (2-ME). Addition of such agents to lymphoid cells in tissue culture has long been known to enhance the viability of the cells remaining after several days in culture (Fanger et al., 1970; Click et al., 1972). When even small numbers of macrophages were added to nonadherent mouse spleen cells in the absence of 2-ME, the viability was shown to be similarly increased (Pierce and Kapp, 1976). However, Pierce and Kapp (1976) have suggested that rather than replacing macrophages in Mishell-Dutton cultures, 2-ME simply augments the activity of the small number of macrophages left in culture after macrophage depletion procedures. This, of course, may be difficult to directly demonstrate until cell populations can be depleted of macrophages so efficiently that they will not respond to cellular antigens under optimal conditions even in the presence of 2-ME.

T cell responses to cellular alloantigens in MLC and CML have also been shown to be supported by factors from cultures of macrophages (Bach et al., 1970) and by 2-ME in mice (Bevan et al., 1974). As discussed earlier, in guinea pigs, rats and humans, macrophages must be present only in the stimulating cell population as the primary stimulating cells. In this respect, they play a dual role of both presenting the alloantigens to the responding $\mathrm{T}$ cells as well as nonspecifically supporting the response (Rosenstreich and Oppenheim, 1976). In addition to $T$ cell responses to alloantigens, $T$ cell proliferative responses to nonspecific mitogens can also be supported by macrophage factors. In the presence of macrophage products, even purified T cells respond well to PHA (Rosenstreich and Oppenheim, 1976). Similarly, the Con $A$ response of $T$ cells requires only macrophage factors. In the situation where macrophage products or thiols such as 2-ME can replace the requirement for macrophages, there is obviously no necessity that the macrophages producing the factors share $\mathrm{MHC}$ components with the responding $\mathrm{T}$ cells.

In contrast to the $T$ cell responses to cellular antigens and mitogens just discussed, $\mathrm{T}$ cell responses to soluble protein antigens have been shown to require the actual presence of viable macrophages in the culture system (for review, see Rosenstreich and Oppenheim, 1976). For these cellular interactions, the MHC does appear to play an important role. This will be discussed in detail in the section on antigen presentation (Section 2.3.2).

\subsection{Mechanisms of Action}

The immunogenicity of many soluble protein antigens appears to be correlated with the ability of in situ macrophages to take up and process the antigen (discussed above 
in Section 2.1). Antigens not taken up well in vivo, and therefore poorly immunogenic, could be preincubated with macrophages and injected as macrophage-bound antigen. Antigens treated in this way were highly immunogenic and never produced tolerance. $B$ cell tolerance to $T$-dependent antigens (all soluble protein antigens are $T$-dependent) has been associated with the prolonged exposure of the $B$ cells to free antigen in the absence of activated helper $T$ cells (for review, see Klaus et al., 1976). One component of the mechanism of increased immunogenicity associated with macrophagebound antigen may be that antigens administered in this way are less likely to be exposed to $B$ cells in free form than are antigens injected without macrophages. All $T$ cell responses to soluble protein antigens, either production of mediators or proliferative responses, require viable macrophages. In addition to preventing prolonged exposure of $B$ cells to antigens, the evidence suggests that macrophages are also needed to present soluble protein antigens to $T$ cells. With these points in mind, we can first discuss antigen processing by macrophages and then the ability of macrophages to present antigens to $\mathrm{T}$ cells.

\subsubsection{Antigen Processing}

Most antigen picked up by macrophages in vitro is endocytosed and broken down into nonimmunogenic fragments (Unanue, 1972; Ellner and Rosenthal, 1975). A small percentage of the antigen associated with the macrophage remains on the cell surface and is highly immunogenic (Unanue, 1972). In mice, the antigen on the surface of macrophages is trypsin-sensitive and can be detected by specific antibody (Unanue et al., 1969b). Further, when mouse macrophages were preincubated with soluble protein antigens and then exposed to antigen-specific antibody or were trypsinized prior to in vivo inoculation, the resulting antibody response was largely abrogated (Unanue, 1972). In guinea pigs the observations are more complex. Walderon et al. (1974) have provided evidence that guinea pig macrophages pulsed with PPD at $4^{\circ}$ and then trypsinized while at $4^{\circ}$ were no longer immunogenic. In contrast, when guinea pig macrophages were pulsed with PPD at $37^{\circ}$, only a fraction of the immunogenicity was trypsin sensitive. Further, when macrophages were pulsed at $4^{\circ}$ and then incubated at $37^{\circ}$ before trypsinization, the macrophage-associated immunogenicity became progressively more trypsin resistant. This led these investigators to postulate two steps in antigen processing by macrophages. The first consisted of antigen binding to the macrophage surface, which was trypsin-sensitive and temperature-independent. The second step involved either internalization or sequestration of the immunogenic component in the folds of the membrane rendering it relatively insensitive to trypsinization. Similarly, Ellner and Rosenthal (1975) have shown that antigen taken up by guinea pig macrophages was resistant to trypsin and could not be detected by specific antibody. They have postulated that the macrophage-lymphocyte interaction might induce a return of the antigen to the surface of the macrophage where it would be available for presentation to $T$ cells. Calderon and Unanue (1974) studied the handling of KLH by macrophages and found that a small percentage (3-7 per cent) of the antigen picked up by macrophages in vitro was internalized and slowly released into the medium as a smaller molecule than the original antigen, and that part of this fragment was still reactive with anti-KLH antisera. This protein release was associated with live macrophages and was trypsin-resistant. In addition, its release was independent of protein synthesis.

In summary, there is general agreement that the majority of the antigen phagocytized by macrophages is degraded into nonimmunogenic fragments and released. This may play an important role in preventing tolerance induction. In addition, a small percentage of the antigen is maintained on the surface of the macrophages where it is highly immunogenic. In mice, the antigen is trypsin-sensitive and detectable by specific antibody. In guinea pigs, the immunogenic fragments are trypsin-resistant and cannot be detected by specific antibody, suggesting they may be sequestered in the membrane. Finally, some of the immunogenic portions of the molecule may be 
internalized, to be slowly released in an immunogenic form for a variable length of time. The biochemical events involved in these processes are largely unknown.

\subsubsection{Antigen Presentation}

2.3.2.1. Antigen presentation by macrophages: effects on $T$ cells. Whereas antigen processing concerns the effects of macrophages on antigens which result in altered and frequently enhanced immunogenicity as compared to the native form, antigen presentation is concerned with the macrophage-lymphocyte interaction which results in antigen-specific triggering of lymphocyte responses. The most recent concepts of antigen presentation by macrophages grew largely out of studies of the genetic control of the immune response. Certain strains of mice (Benacerraf and McDevitt, 1972), guinea pigs (Paul and Benacerraf, 1974) and rats (Kunz and Gill, 1974) have been found to be high or low antibody responders to specific antigens. The ability to mount a strong antibody response to many antigens was linked to the MHC (Benacerraf and McDevitt, 1972; Kunz and Gill, 1974). By use of recombinant strains of mice for genetic mapping, the immune response (Ir) genes have largely been found to be located in the I region of the $\mathrm{MHC}$ although in some cases the $\mathrm{H}-2 \mathrm{~K}$ region has not yet been ruled out (Shreffler and David, 1975). Ir gene expression, or the ability to generate immune responses to antigens under Ir gene control, was once thought to be primarily a property of T cells (Paul and Benacerraf, 1974). Now, however, macrophages in the guinea pig (Shevach, 1976) and the rat (Tada et al., 1976) and probably B cells, in some cases in mice (Mozes and Shearer, 1971), are thought to express Ir genes. The I region of the MHC also codes for I region-associated (Ia) cell surface antigens found on the membranes of subpopulations of $T$ cells, $B$ cells and macrophages as well as some nonlymphoid cells (Hammerling, 1976). That Ia antigens are important in macrophage- $T$ cell interactions is indicated by the fact that antisera directed toward these Ia antigens have been shown to block $T$ cell proliferative responses to macrophage-bound soluble antigen (Shevach and Rosenthal, 1973; Shevach, 1976). Further, recent evidence has been presented that antisera directed toward Ia antigens coded for in the I-J subregion of the MHC (recently described by Murphy et al., 1976), when preincubated with macrophages but not the macrophage-depleted responding lymphocytes, could block the in vitro humoral response to burro red blood cells (BRBC) (Neiderhuber and Shreffler, 1976). Studies of lymphoid cellular interactions have suggested that $\mathrm{T}$ cell-B cell collaboration in vitro and in vivo required identity at various I subregions of the MHC (Katz et al., 1973a, 1976). Similar requirements have been suggested for the ability of macrophages to present antigens to $T$ cells for helper cell induction (Erb and Feldmann, 1975b, 1976) and for induction of antigen-specific T cell proliferative responses (Rosenthal and Shevach, 1973). However, exceptions to this rule have been reported. Pierce et al. (1976) and Kapp et al. (1973) have shown that completely allogeneic macrophages can prime $T$ cells in vitro to become helper cells for antibody-forming cell (AFC) production to GAT (a random terpolymer of L-glutamic acid-L-alanine-L-tryosine). In addition, HeberKatz and Wilson (1976) have shown rat $T$ cells, 'filtered' through irradiated $F_{1}$ hybrid rats to deplete alloreactive cells, could collaborate with allogeneic B cells in a primary in vitro anti-SRBC response. These experiments, then, suggest that Ia compatibility may not be required for cellular interactions of unprimed cells.

Similar experiments have been performed in vivo. Bechtol et al. (1974) have used tetraparental (allophenic) chimeric mice constructed from the fusion of mouse embryos of strains which are high (CWB) and low $(\mathrm{C} 3 \mathrm{H})$ responders to Poly $\mathrm{L}-(\mathrm{Ty}$, Glu)-poly-D, L-Ala-poly-L-Lys (TGAL). These strains are congenic on the C3H background, differing for the Ig allotype and the $\mathrm{H}-2$ complex. The percentage of each parental lymphoid cell type in the adult chimeric mice could be determined by allotype analysis of the serum immunoglobulin. Those mice with a high percentage of the CWB Ig allotype proved to be high responders to TGAL and those with a low percentage of the CWB allotype were poor responders. This suggested that the 
genetic responsiveness was still associated with the predominant lymphoid cell type in the chimeric mice. However, when high responder chimeric mice were immunized with TGAL, the anti-TGAL response consisted of antibody of both allotypes and the ratio of the $\mathrm{CWB}$ allotype to the $\mathrm{C} 3 \mathrm{H}$ allotype had not changed from the resting state. This suggested that $\mathrm{B}$ cells of both haplotypes responded to CWB $\mathrm{T}$ cell help, thus providing evidence that $\mathrm{T}-\mathrm{B}$ collaboration could occur in vivo despite MHC differences. These observations were further supported by the experiments of von Boehmer et al. (1975a). They adoptively transferred, into lethally irradiated $F_{1}$ mice, SRBC primed $T$ cells from tetraparental bone marrow chimera mice which were depleted of cells from the other parental donor by treatment with alloantisera and complement. The recipients were then inoculated with SRBC and with SRBC-primed $B$ cells depleted of $T$ cells by anit-theta plus complement from the opposite parental strain. These allogeneic, primed $\mathrm{T}$ and $\mathrm{B}$ cells cooperated well to give a strong anti-SRBC response. Since these investigators (von Boehmer et al., 1975b) had previously demonstrated the lack of alloreactivity between $T$ cells from chimeric mice and cells from mice of one of the parental strains, the observed response was not due to an allogeneic effect. Similarly, Bechtol et al. (1976) have provided convincing evidence that the anti-TGAL responses (discussed above) in $\mathrm{C}_{3} \mathrm{H} \leftrightarrow \mathrm{CWB}$ tetraparental mice were in no way due to an allogeneic effect. These experiments have clearly shown that, at least in some situations, $\mathrm{T}$ cells and B cells can collaborate in vivo despite I region differences. To provide an explanation for these observations, Pierce et al. (1976) have recently pointed out that the Ia identity requirement had been seen in experiments using primed cells in secondary responses, whereas those investigators not observing the Ia identity genetic restriction had tested either primary responses or responses of $\mathrm{T}$ cells primed in a chimeric environment (Kapp et al., 1973; Pierce et al., 1976; Heber-Katz and Wilson, 1975). Further, Pierce et al. (1976) demonstrated that $T$ cells primed in vivo with allogeneic macrophages required macrophages syngeneic to those used for priming, to trigger a secondary response. Moreover, macrophages syngeneic to $\mathrm{T}$ cells primed with allogeneic macrophages could not be substituted for allogeneic macrophages for the secondary challenge. These findings are supported by the work of Miller et al. (1976a), using an adoptive transfer of delayed hypersensitivity (DTH) system in mice. They have shown that $T$ cells of one parental haplotype, sensitized in a chimeric environment, could adoptively transfer DTH to either of the parents despite total histoincompatibility. Further, $T$ cells from $(B A L B / c \times C B A) F_{1}$ hybrid mice, sensitized in either $B A L B / c$ or $C B A$ nude mice, could transfer DTH reactivity only to the parent syngeneic to the nude mouse in which they were sensitized (Miller et al., 1976a). They previously showed that $F_{1}$ cells sensitized in an $F_{1}$ environment could transfer DTH reactivity equally well to either parent (Miller et al., 1976b). These experiments support the notion that the original macrophage- $T$ cell interaction is responsible for genetic restrictions observed for macrophage interactions with primed $T$ cells. More direct evidence for this hypothesis has been provided by recent reports of Thomas and Shevach (1976, $1977 \mathrm{a}, \mathrm{b}$ ). They showed that purified lymph node cells of (strain $2 \times$ strain 13) $\mathrm{F}_{1}$ guinea pigs, primed in vitro with OVA-pulsed macrophages from either parent, could be restimulated only with macrophages of the same parent pulsed with the same antigen. In contrast, $F_{1}$ LNC primed with $F_{1}$ macrophages would respond to either of the parental macrophages in a secondary response (Thomas and Shevach, 1976). These experiments, however, only showed priming of $F_{1} L N C$ by macrophages, albeit with interesting genetic restrictions for subsequent $T$ cell restimulation. To examine priming of $T$ cells with totally allogeneic macrophages, they had to pretreat the macrophages with specific anti-Ia antisera to block alloantigen sensitization which would otherwise result in a strong secondary MLC upon reexposure of the allogeneic macrophages to the allosensitized $T$ cells. They found that the antisera, in addition to blocking the Ia determinant on the macrophages, served as an antigen to which the $T$ cells could be sensitized. Once primed, the $T$ cells responded secondarily only to macrophages of the same haplotype which were treated 
with anti-Ia antisera. Neither macrophages of the proper haplotype without pretreatment with anti-Ia, nor syngeneic macrophages regardless of treatment with anti-Ia stimulated. Therefore, this represents a clear example of $T$ cell priming with histoincompatible macrophages, the secondary response of which was specific not only for the antigen but also for the haplotype of the macrophage used for the initial priming. Further, these investigators found that antisera toward the B.1 MHC determinant (analogous to the $\mathrm{H}-2 \mathrm{~K}$ and $\mathrm{D}$ regions in the mouse) also could act as an antigen and that the Ia genetic restriction for secondary stimulation was operative in this case also. On the basis of these data, they have suggested that protein antigens bound to Ia and other MHC molecules on macrophages serve as 'complex antigenic determinants' to which $\mathrm{T}$ cells are primed. Moreover, they concluded that Ia antigens must indirectly influence the presentation of antigen bound to other MHC molecules since only anti-B.1 treated macrophages with Ia determinants identical to those of the anti-B.1 treated macrophage used for priming could elicit a secondary proliferative response (Thomas and Shevach, 1977a). In addition, they have shown that TNPmodified macrophages could specifically sensitize allogeneic $\mathrm{T}$ cells, but only after the alloreactive clone of $\mathrm{T}$ cells was depleted by treatment with BUdR and light during a primary MLC. The reason for this was not obvious, but since not even syngeneic macrophages, modified with TNP, could sensitize T cells during a MLC proliferative response, it was likely that a suppressor mechanism was being generated which was dependent on the proliferation of the alloreactive cells (Thomas and Shevach, 1977b).

Paul et al. (1976) have recently shown that guinea pig LNC primed in vivo with OVA could be restimulated in vitro with antigen-pulsed macrophages from either parent, and if during the proliferative phase of the secondary response induced by such antigen-pulsed macrophages, the responding cells were treated with BUdR and exposed to light, thus eliminating the proliferating clone, the remaining cells could be stimulated only with OVA-pulsed macrophages from the alternate parent. Positive selection experiments showed that if $F_{1} L N C$, primed in vivo, were restimulated with OVA-pulsed macrophages of one parent, the responding cells were then hyperresponsive for OVA-pulsed macrophages of that parent but only modestly responsive to OVA-pulsed macrophages of the other parent.

All of these data can be explained by the hypothesis that the original macrophage-T cell MHC relationship established a preference in the secondary response for macrophage MHC antigen which induced the primary response. I, D and $\mathrm{K}$ region identity primary sensitization, $T$ cells appear to recognize antigens in complex or association with MHC antigens on macrophages. For secondary stimulation then, the primed $\mathrm{T}$ cell requires presentation of antigen in complex or association with the same macrophage MHC antigen which induced the primary response. I, D, and $\mathrm{K}$ region identity requirements for secondary $\mathrm{T}$ cell stimulation have been demonstrated depending on the antigen used (Miller et al., 1976a; Paul et al., 1976; Thomas and Shevach, 1976; Pierce et al., 1976). In the case of $F_{1}$ cells sensitized in an $F_{1}$ environment, or parental cells sensitized in a chimeric environment, two clones of antigen-reactive cells may be generated, one for each macrophage haplotype expressed during the sensitization.

In summary, these recent observations indicate that MHC gene products on macrophages play a critical role in the sensitization process of the $T$ cell and that $T$ cell receptors recognize antigen in complex or association with macrophage Ia or other MHC determinants. Paul et al. (1976) have postulated that the MHC has evolved as the basis for cellular interactions which are essential for the competence of the immune response. This interesting hypothesis serves to point out the rather central role of macrophages in induction of $\mathrm{T}$ cell-dependent immune responses.

2.3.2.2. Antigen presentation by macrophages: effects on $B$ cells. In contrast to the recent advances in understanding of the macrophage- $T$ cell interaction, the macrophage-B cell interaction has received little attention. Rather, the $\mathrm{T}$ cell-B cell interaction has been stressed (Katz et al., 1973a, b, 1976; reviewed in Katz and Benacerraf, 1972). The demonstration that $T$-independent $B$ cell antigens were also 
macrophage independent (Shortman et al., 1970; Mosier et al., 1974; Feldmann, 1972a, b) has suggested that the primary or sole role of macrophages is to sensitize $T$ cells and only through that mechanism could macrophages influence $B$ cell responses. However, recent demonstrations that $B$ cell responses to some $T$-independent antigens either require or are greatly enhanced by macrophages (Chused et al., 1976; Lee et al., 1976; Pike and Nossal, 1976) suggest that macrophages may play a role in B cell activation and that their effect on B cells in these responses may have been overlooked. There is, in fact, some evidence that activated macrophages produce factors that can stimulate $B$ cells directly to respond to $T$-dependent antigens in the absence of T cells (Schrader, 1973; Wood and Gaul, 1974; Hoffman et al., 1976a, b; Wood and Cameron, 1975). In addition, there is evidence that $T$ cell helper factors may require macrophages to activate (or provide a second signal for) $B$ cells. Feldmann (1972c) has reported experiments done in double chambered Marbrook vessels in which primed $\mathrm{T}$ cells, separated from $\mathrm{T}$ cell-depleted spleen cells by a $0.1 \mu$ Nucleopore membrane, could induce specific AFC production by the $T$ cell-depleted spleen cells in the presence of the priming antigen (DNP-KLH). When macrophages were also depleted from the T cell-depleted spleen cells, no specific AFC production could be demonstrated. Reconstitution of the spleen cells with purified anti-theta and complement-treated PEC (macrophages) again resulted in specific AFC production. Further, when primed $T$ cells were cultured in the upper chamber of the Marbrook vessel with DNP-KLH, and purified PEC were cultured alone in the lower chamber, Feldmann (1972c) found that the thoroughly washed PEC could induce a strong antigen-specific AFC response when combined with $\mathrm{T}$ cell-depleted spleen cells in a secondary culture devoid of additional antigen. From such experiments, Feldmann (1972c) concluded that macrophages were required to present the antigen-T cell factor complex to B cells. Schrader and Feldmann (1973) arrived at similar conclusions during investigations of antigenic competition. In these experiments, mice which had been primed with fowl gamma globulin (FGG) were injected with donkey RBC (DRBC) i.p. or i.v. 2 days before serving as donors of spleen cells to be used in a Marbrook-Diener culture system to produce AFC to DNP coupled to FGG. They found that the AFC response was very poor when DNP-FGG was used as an antigen, but when DNP was coupled to a thymus-independent antigen such as flagella (FLA), a strong AFC response was observed. This indicated that the B cells were fully competent to produce antibody when triggered by a $\mathrm{T}$-independent antigen and suggested the defect in the response to DNP-FGG was in either the $T$ cells or the macrophages. They found that addition of very small numbers of normal macrophages to the system ( 0.2 per cent of the responding cells) allowed a normal AFC response, compared to the response of cells from FGG-primed mice not preinjected with DRBC. In addition, the ability to respond to DNP-FGG was restored by trypsinizing the responding cells prior to culture. From these experiments, they concluded that macrophages in the spleens of mice pre-injected with DRBC were unable to present the $T$ cell helper factor to the $B$ cells due to the pre-injection with DRBC in vivo. The trypsinization, they concluded, acted to remove a surface inhibitor from the surface of the macrophages.

Further evidence that macrophages alone can enhance B cell antibody production was provided by Opitz et al. (1976). They showed that normal mouse spleen cells would generate a polyclonal antibody response in a Mishell-Dutton culture system if cocultivated with high concentrations of mouse PEC for $8 \mathrm{hr}$ before depleting the spleen cells of all phagocytic cells and reculturing them in media containing 2-ME. Control cultures not cultured with high numbers of mouse PEC generated no such response.

In summary then, these observations suggest that macrophages can have significant effects on $B$ cell responses to both $T$-dependent and $T$-independent antigens. In view of the recent work describing the mechanisms of antigen presentation to $T$ cells by macrophages (previous section), it seems likely that macrophages may also be involved in the presentation of $T$ cell-dependent helper factors to $B$ cells. Alter- 
natively, primed $\mathrm{T}$ cells, upon activation by antigen, may liberate factors which activate macrophages which then provide a second signal to B cells for specific AFC production. Considering the changing concepts of the genetic restrictions (or lack thereof) on $\mathrm{T}$ cell-B cell collaboration and macrophage-T cell interactions, it would seem that further investigations are needed on the role of macrophages in the relationship between $T$ cells and $B$ cells as well as their role in stimulating B cells directly.

\section{SUPPRESSION OF IMMUNE RESPONSES BY MACROPHAGES}

In the previous sections we have discussed evidence that macrophages can enhance immune responses in vivo and in vitro. Various mechanisms were discussed, both in terms of the effect of macrophages on the antigen itself and the requirement for macrophages of various lymphocyte responses to antigens and mitogens. In most cases, normal macrophages in very low concentrations were used to demonstrate these enhancing effects.

In this section, we shall concentrate on suppressive effects of macrophages on the immune response. In contrast to the enhancing effects, the suppressive effects have usually been seen with greater concentrations of macrophages or with highly activated macrophages. First, we shall describe a series of basic observations made in our laboratory and in others which provide a framework on which a more general concept of immunosuppression resulting from the inhibition of lymphocyte proliferation by cells of the reticuloendothelial system (RES) can be constructed. What is known about the mechanism of macrophage-mediated cytostatic effects will be reviewed. We suggest that 'activation' of macrophages is a relative term and that the degree of suppression is related not only to the activation state of the macrophages but also to the number of macrophages in the proximity of an expanding clone of lymphocytes. We shall discuss various ways in which macrophages can become activated and thereby become more suppressive. An important recent finding which will be emphasized is that $T$ cells can generate suppressor macrophages via a factor isolated from Con A-induced suppressor $T$ cells. Therefore, suppressor $T$ cells may exert their effects indirectly through activation of suppressor macrophages.

We shall then discuss the evidence that suppressor macrophages in vitro and an activated reticuloendothelial system (RES) in vivo can be shown to have similar effects on lymphocyte responsiveness. A number of examples of suppressed immune responses associated with an activated RES will be discussed, along with evidence that in many cases the cell which mediates the suppressor effect is probably an activated macrophage. Finally, we shall discuss the observations that macrophages, usually considered to be nonspecific in their effects, may in fact be able to distinguish between neoplastic and non-neoplastic cells.

\subsection{Basic Observations}

Our laboratory has recently investigated a number of cases of suppressed immune responses in vitro and, in many instances, has identified the responsible agent as a macrophage (Kirchner et al., 1974a, b, c, 1975a, b; Oehler et al., 1977a, b; Fernbach et al., 1976a, b; Glaser et al., 1976; reviewed in Kirchner et al., 1976). Many of the original observations were made by Kirchner et al. (1974a, b, 1975a). It was initially observed that spleen cells from C57BL/6 mice bearing tumors induced by inoculation with Moloney sarcoma virus (MSV) responded poorly if at all to $T$ cell mitogens such as PHA and Con A and frequently had a depressed response to the B cell mitogen LPS (Kirchner et al., 1974a, b). There were several possible explanations for such findings. If $T$ cells, and occasionally $B$ cells, migrated from the spleen during the growth of the tumor, the lack of cells even potentially capable of responding to mitogens when cultured in vitro could account for the defect. However, purification of the lymphocytes by passing the spleen cells from MSV tumor-bearing mice (MSV 
spleen cells) over a rayon adherence column [a technique by which cells capable of ingesting latex particles were largely depleted but the ratio or surface immunoglobulin (Ig) positive to Ig negative cells was essentially unchanged (Kirchner et al., 1974a)] reconstituted the proliferative response to the mitogens (Kirchner et al., 1974a, b). Therefore, cells capable of responding to the mitogens were present in the spleen. Thus two possible explanations remained: either the potentially responsive cells were diluted by an influx of cells which would not respond to mitogens (Smith and Konda, 1973), or a population of adherent cells was present which somehow prevented the potentially responsive cells from proliferating. To test whether a suppressive effect was playing a role in the failure of the MSV spleens to respond to mitogens, spleen cells from MSV tumor-bearing mice were mixed with spleen cells from normal mice and the mixture was incubated with PHA. Virtually no proliferative response was observed in the cell mixture, demonstrating the role of suppressor cells (Kirchner $e t$ al., 1974b). To characterize the cell or cells responsible for the suppressive effect, a number of subpopulations of cells from MSV spleens were tested for their suppressive effects on the proliferative response of normal spleen cells to PHA. Pretreatment of the MSV spleen cells with anti-theta and complement to remove $T$ cells had no effect or actually increased the suppressive effects (Kirchner et al., 1974b, 1975a). In contrast, depletion of adherent cells by passage over a rayon column, or of phagocytic cells by pretreatment with iron powder and magnet, totally abrogated the suppressive effect (Kirchner et al., 1974b). In addition, pretreatment of the cells with carrageenan, which is specifically toxic for macrophages and not for lymphocytes (Lake et al., 1971), largely abrogated the suppression (Kirchner et al., 1975a). Further, the suppressor activity was resistant to $2500 \mathrm{r}$ X-irradiation (Kirchner et al., 1975a). These data indicated that the MSV spleen cells contained a subpopulation of radioresistant, phagocytic, carrageenan-sensitive, non- $T$ cells, and thus probably macrophages or monocytes, which could suppress the proliferative response of lymphocytes to mitogens (reviewed in Kirchner et al., 1976). Subsequent reports concerning studies of tumor-bearing rats (Glaser et al., 1975; Veit and Feldman, 1976b), humans (Broder et al., 1975) and mice (Pope et al., 1976) confirmed that suppressed responses to mitogens could be due to the presence of a population of suppressor macrophages. In addition to the suppression of mitogen responses, macrophage-mediated suppressive effects have been demonstrated in a variety of other in vitro reactions. Fernbach et al. (1976b) found that MSV spleen cells responded poorly to alloantigens in MLC and CML. When mixed with normal mouse spleen cells, irradiated MSV spleen cells were strongly suppressive compared to the effect of adding equal numbers of irradiated normal spleen cells. When MSV spleen cells were pretreated with carrageenan or when the phagocytes were depleted with iron and magnet, the suppressive effect was no longer seen. In addition, the cells were found to be adherent and radioresistant. As expected, treatment with anti-theta and complement had no effect. Addition of peritoneal exudate cells (PEC), induced with thioglycolate and purified by Petri dish adherence so that greater than 95 per cent of the cells were macrophages morphologically, also resulted in suppression of the MLC and the CML (Fernbach et al., 1976a). Berlinger et al. (1976) have shown that depressed MLC responses of PBL from some cancer patients could be restored by passing the PBL over a Sephadex G-10 column which in their hands selectively depleted monocytes. Kirchner et al. (1975a) found that the $T$ cell proliferative response of spleen cells from tumor-bearing mice to tumor-associated antigens in a mixed lymphocyte-tumor interaction (MLTI) was greatly improved by depletion of adherent or phagocytic cells. Similarly, Glaser et al. (1975) showed that spleen cells taken from rats bearing progressively growing tumors were largely unresponsive to tumor-associated antigens in a MLTI. After deptetion of adherent or phagocytic cells, positive responses were detected. We recently confirmed and extended these observations, and have shown that the suppressor cells in tumor-bearing rats were resistant to treatment with a specific heterologous anti-rat thymocyte serum and complement 
(ATS and C) as well as to a heterologous anti-rat immunoglubulin serum and complement (Oehler et al., 1977a). These data indicated that the suppressor cells in spleens of tumor-bearing rats which inhibit specific lymphoproliferative responses to tumor cells in vitro were macrophages. In rats, however, we found that normal spleen cells added to MLTI cultures as third parties were also suppressive, albeit not as suppressive as spleen cells taken from tumor-bearing donors. Extensive characterization procedures showed suppressor cells in the spleens of non-tumor-bearing rats similarly were macrophages. These experiments indicated that the suppressive nature of macrophages may not necessarily represent a pathologic state but rather reflect a normal regulatory mechanism which is intensified in some pathological conditions.

Injection of 'mice with agents such as heat-killed Corynebacterium parvum ( $C$. parvum) results in a strong stimulation of the reticuloendothelial system (RES) (Halpern et al., 1963; Halpern, 1975). Splenic macrophages from mice treated with $C$. parvum, strongly supress the lymphoproliferative responses to PHA, Con A and LPS, and, if given in a high enough dose, to pokeweed mitogen (PWM) (Scott, 1972; Kirchner et al., 1975c; reviewed in Kirchner et al., 1976). Mitchell et al. (1973) have shown similar effects after treatment of mice with Bacillus Calmette-Guerin (BCG).

In contrast to the inhibitory effects of suppressor macrophages on proliferative responses and on the generation of cytotoxic lymphocytes which require proliferation (Cantor and Jandinski, 1974; Peavy and Pierce, 1975), cytotoxicity by previouslygenerated effector cells seems not to be affected. Primary T cell-mediated cytotoxicity to tumor-associated antigens (Kirchner et al., 1974b), PHA-induced T cell-mediated cytotoxicity (Kirchner et al., 1975a) and antibody-dependent cell-mediated cytotoxicity (Poplack et al., 1976; reviewed in Kirchner et al., 1976) appear to be unaffected by suppressor macrophages. Thus, immune cell functions which are independent of proliferation may not be sensitive to suppression by macrophages. It seems likely that a major mechanism of action of suppressor macrophages is inhibition of lymphocyte proliferation, with consequent limitation of the expansion of an antigen-sensitive clone of effector lymphocytes. Keller (1974a) has emphasized the need for macrophages to be activated to mediate the suppressor effect. His data show that on a per cell basis, peptone broth-induced rat peritoneal macrophages are more suppressive than non-induced peritoneal macrophages. However, in sufficient concentrations, 'resting' or non-induced macrophages also inhibited lymphocyte proliferation (Keller, 1974a). Our laboratory has provided further evidence, in both mice (Fernbach et al., 1976a) and rats (Oehler et al., 1977b), that by simply increasing the concentration of PEC in MLC-CML cultures, lymphoproliferative responses and the resultant generation of cytotoxic effector cells were inhibited without affecting the viability of the cells in the suppressed cultures. Further, the distinction between 'activated' and 'resting' macrophages is complicated by the fact that many substances including lymphocyte mediators (reviewed by David, 1975), with which circulating macrophages must to a variable degree be in contact in vivo, activate macrophages. Therefore, it may be better to think of relative degrees of activation rather than of an all or none phenomenon. This would account for both Keller's (1974a) findings that activated macrophages were more suppressive than resting (less activated) macrophages and our observations that increased numbers of peritoneal macrophages added to CML cultures as third parties [5-8 per cent in rats (Oehler et al., 1977b) and greater than 10 per cent in mice (Fernbach et al., 1976a)] were strongly suppressive. In contrast, addition of a thirty fold greater number of $X$-irradiated thymocytes to rat $C M L$ cultures as third parties had no suppressive effect, suggesting that cell crowding was not the cause of suppression by higher numbers of macrophages (Oehler et al., 1977b). Thus, it would appear that macrophages, either low numbers of strongly activated cells or higher numbers of minimally activated cells, can suppress lymphocyte proliferation and in that way inhibit or abrogate the expansion of a clone of sensitized lymphocytes. 


\subsection{Mechanisms of Action}

\subsubsection{Assay Systems}

Much of the information concerning the mechanisms of macrophage-mediated suppression has come from the work of Keller (1974a, b, 1976; Keller et al., 1975) who measured the rate of proliferation of antigen- or mitogen-triggered lymphocytes in Petri dishes containing various concentrations of purified macrophages obtained from rat peritoneal exudates. Basically, Keller demonstrated that high macrophage to lymphocyte ratios (10:1) completely inhibited proliferation of the lymphocytes (Keller, 1975). The effect was nonspecific in that the proliferation of syngeneic, allogeneic, and xenogeneic lymphocytes could be suppressed. Moreover, use of malignant lymphoma cells as targets of suppression has provided a consistent and simpler assay system for analysis of the mechanism of the macrophage-mediated suppression (Keller, 1974a), since these cells did not need to be stimulated to proliferate.

Support for the use of rapidly dividing tumor cells as indicator cells for suppressor macrophage activity has recently been provided by our laboratory (Oehler et al., 1977a). We have directly compared the ability of macrophages to suppress the proliferation rate of lymphoma lines maintained in vitro to their ability to suppress specific lymphoproliferative responses of immune rate splenic $\mathrm{T}$ cells to tumorassociated antigens in a mixed lymphocyte-tumor interaction (MLTI). Under the proper conditions, results obtained in one assay could be used to predict results obtained in the other. This indicated that the cytostatic mechanism was similarly effective on rapidly proliferating lymphoid cells regardless of the stimulus (Oehler et al., 1977a).

\subsubsection{Metabolic Requirements for Macrophage-Induced Suppression}

Keller (1974b) has evaluated the effects of various agents and treatments to determine the metabolic requirements for macrophage-induced suppression. The suppressive effect was sensitive only to protein synthesis inhibitors and inhibitors of glycolysis (Keller, 1974b). When various parameters of macrophage activity were monitored, such as cellular adherence, pinocytosis, bactericidal capacity, glucose oxidation, production of RNase and DNase, and others, only alterations in the rate of protein synthesis correlated with the cytostatic effects observed (Keller, 1975). Pretreatment of macrophage monolayers with inhibitors of DNA synthesis such as mitomycin $\mathrm{C}$ and $\mathrm{X}$-irradiation had no effect on their cytostatic activity. In addition, the suppressor activity was resistant to treatment with a variety of enzymes including trypsin, neuraminidase and pronase. Inhibitors of pinocytosis or phagocytosis had no effect. Moreover, careful microscopic examination of the experimental cultures showed no relationship of increased phagocytic activity to the degree of suppression. Thus, although the mechanisms by which macrophages inhibit lymphoproliferative responses are unknown, the available evidence suggests that the ability to suppress can be correlated with the rate of protein synthesis and not with various other parameters of macrophage activation. This could be interpreted to suggest that only a subpopulation of macrophages, characterized by its increased rate of protein synthesis, is suppressive or that only macrophages which have been activated to undergo increased protein synthesis are suppressive. However, until these findings are confirmed in other laboratories, it may be premature to speculate on the mechanisms by which suppressor macrophages mediate their effects.

\subsubsection{Suppressor Effects of Macrophages Mediated by Soluble Factors}

Although there are a number of reports describing suppressor effects of macrophages which require cell-cell contact (Sjöberg and Britton, 1972; Sjöberg, 1971; Eggers and Wunderlich, 1975; Kirchner et al., 1975a; reviewed in Kirchner et al., 1976), macrophages also appear to mediate suppressor effects through the effects of soluble factors (for review see Modulation of Immunity by Soluble Mediators by Byron H. Waksman, in this series). Suppressor factors produced by or dependent on 
macrophages have been described by a number of investigators. Calderon et al. (1974) have described a factor recovered from cultures of mouse peritoneal exudate cells which inhibited ${ }^{3} \mathrm{H}$-TdR incorporation by, and proliferation of, tumor cells and mitogen-stimulated lymphocytes in vitro. It was of low molecular weight and resistant to trypsin digestion. Further, it could be absorbed by tumor cells cultured in vitro. Similarly, Waldman and Gottleib (1973) have described a low molecular weight factor isolated from rat PEC which inhibited proliferation of antigen-stimulated and resting rat lymphocytes. Krakauer et al. (1976) have demonstrated a soluble suppressor factor which inhibited immunoglobulin production of PWM-stimulated mouse spleen cells. This factor was apparently produced by macrophages in the ascitic fluid of hypogammaglobulinemic mice bearing plasmacytomas. Similarly, Kolb et al. (1977) have demonstrated a suppressor factor apparently originating from macrophages of mice bearing large plasmacytomas which inhibited the PFC response to SRBC in MishellDutton cultures.

Caution must be exercised, however, in evaluating the effects of soluble factors produced from lymphoid cells in tissue culture. When only one parameter such as ${ }^{3} \mathrm{H}-\mathrm{TdR}$ incorporation is used as a measure of suppression, the possibility that breakdown products of dying cells are present in the culture which compete with radiolabeled DNA precursors and thus inhibit ${ }^{3} \mathrm{H}-\mathrm{TdR}$ incorporation without inhibiting cell proliferation must be ruled out. One group (Opitz et al., 1975a), in fact, has performed a series of biochemical characterizations on a soluble factor which they had previously shown to suppress ${ }^{3} \mathrm{H}-\mathrm{TdR}$ incorporation of PHA-stimulated mouse lymphocytes (Opitz et al., 1975b) and conclusively demonstrated that it was thymidine. There are several ways to avoid such tissue culture artifacts. One way is to use a second assay system independent of ${ }^{3} \mathrm{H}$-TdR incorporation to demonstrate the suppressive effect. Fernbach et al. (1976a) showed that macrophages suppressed the generation of cytotoxic effector cells and the appearance of blast cells as well as the incorporation .of ${ }^{3} \mathrm{H}-\mathrm{TdR}$ by mouse $\mathrm{T}$ cells in MLC. In this study, by observing the effects of various concentrations of macrophages on the MLC, they noted that ${ }^{3} \mathrm{H}$ TdR incorporation was inhibited at a slightly lower concentration of macrophages than was the generation of lymphoblasts or the generation of cytotoxic effector cells. It seems likely that the slightly disparate findings were a result of the presence of cell breakdown products in the media. This effect, however, was minor compared to the effect of greater numbers of macrophages which totally suppressed all three parameters of the response generated in the MLC.

In addition to using alternate assay systems, one can measure the incorporation of other labeled protein or nucleic acid precursors such as tritiated uridine, valine or leucine. Opitz et al. (1975a) showed that the incorporation of these precursors was not inhibited by supernatants from cultures containing cell breakdown products which artifactually inhibited ${ }^{3} \mathrm{H}-\mathrm{TdR}$ incorporation. Similarly, Fernbach et al. (1976a) have suggested that the use of low specific activity ${ }^{3} \mathrm{H}-\mathrm{TdR}(300 \mathrm{mCi} / \mathrm{mm}$ instead of $6 \mathrm{Ci} / \mathrm{mm}$ ) minimized the effect of artifactual ${ }^{3} \mathrm{H}-\mathrm{TdR}$ incorporation inhibition. Perhaps the easiest way to avoid such artifacts is to wash the cells immediately before addition of ${ }^{3} \mathrm{H}-\mathrm{TdR}$, thus removing any cell breakdown products which may have accumulated during the culture period.

Thus, in light of the findings of Opitz et al. (1975a), who identified their low molecular weight suppressor factor as thymidine, it seems mandatory that any soluble suppressor substance which inhibits ${ }^{3} \mathrm{H}-\mathrm{TdR}$ incorporation of proliferating cells in vitro must be shown to actually inhibit cellular proliferation to be seriously considered as a factor which may have immunosuppressive activity in vivo.

\subsubsection{Macrophage Activation as a Result of Interaction with Exogenous Agents or with Lymphocytes and Their Mediators}

As previously discussed, macrophages which are in states of increased activation, usually associated with increased rates of protein synthesis, are more suppressive on a per cell basis than less activated macrophages. A number of agents are known to 
stimulate the reticuloendothelial system (RES) which results in the appearance of highly activated macrophages in the organs of the lymphoid system and particularly in the spleen. Similar effects on the activation of macrophages by such agents have been observed in vitro. First, we will discuss exogenous agents which activate macrophages and the little that is known about the mechanisms involved. Then we will discuss possible mechanisms by which suppressor macrophage activity may be enhanced or regulated by interaction with lymphocytes or their mediators during the induction of an immune response.

Several agents capable of activating macrophages are known. Bacterial products can activate macrophages. Shilo (1959) has reviewed evidence that in the case of gram negative bacteria, the lipopolysaccharide component of the cell wall, and particularly the lipid A component, is a potent macrophage activator. Other macrophage activators include certain organisms such as C. parvum (Halpern et al., 1964), Listeria monocytogenes, BCG, Mycobacterium tuberculosis (reviewed by McGregor and Logie, 1975) and double-stranded RNA (reviewed by Allison and Davies, 1975). The actual mechanism of macrophage activation by these agents is unknown. C. parvum has been extensively studied to learn why it is such a powerful RES stimulant. Prévot (1975) has suggested that a component of the bacterial cell wall is responsible for the intense RES activation and has tentatively named it 'reticulostimulin'. Efforts to purify reticulostimulin, however, have largely resulted in abrogation of the macrophage-activating effect (Adlam et al., 1975) and thus have been unsuccessful. In addition to microbial agents such as $C$. parvum, most soluble adjuvants are known to stimulate reticuloendothelial proliferation and to activate macrophages (Unanue et al., 1969a). Spitznagel and Allison (1970) have correlated the ability of various substances to labilize lysosomes in macrophages with their adjuvant effects. They found that retinol (vitamin A alcohol) and LPS were particularly active in this respect. Despite the large number of empirical observations that the administration of various agents such as those mentioned above results in RES activation, very little is known about the actual mechanisms involved. It seems likely that a greater understanding of the mechanisms of this important aspect of the immune response will enable such agents to be used as one of the means of intervening in and regulating the immune response in the future.

In addition to interaction with exogenous agents, macrophage-lymphocyte interactions also have been shown to result in activation of macrophages. Similar to the requirement for macrophages for the sensitization phase of most immune responses (discussed earlier in this review), macrophages have also been shown to be required to mediate the effector phase of the response in collaboration with sensitized lymphocytes in some cases. McGregor and Koster (1971) have shown that lasting immunity to Listeria monocytogenes in rats can be adoptively transferred with thoracic duct lymphocytes, but cannot be mediated without an intact macrophage system. Conversely, purified macrophages from immune animals could not transfer lasting immunity even to intact animals. These results suggest that certain immune effector functions require an interaction between immune $T$ cells and macrophages which neither cell alone can carry out regardless of the immune status. Nathan et al. (1973) have studied mediators from T lymphocytes which affect macrophages. They found macrophage migration inhibition factor (MIF) to be particularly active in increasing macrophage adherence, phagocytosis, and glucose carbon 1 oxidative hexose monophosphate shunt pathway metabolism. Moreover, they found that interaction of macrophages with MIF also results in increased protein synthesis. Two to three days of exposure to the lymphokine in vitro was required before the effects became detectable in their system (Nathan et al., 1971). In a recent review of the effect of lymphocyte mediators on macrophages, David (1975) has confirmed and extended the reports of Nathan et al. (1973). He discussed evidence that, in addition to the metabolic and morphologic effects on macrophages attributed to MIF by Nathan et al. (1973), MIF also decreased lysosomal enzymes, increased the cytoplasmic enzyme lactic dehydrogenase, as well as membrane adenylate cyclase, and 
increasea glucosamine incorporation. More importantly, bacteriostasis to Listeria monocytogenes and tumoricidal activity have been shown to be strongly enhanced.

Thus, there is ample evidence that macrophages can be activated by interaction with a number of agents including lymphocyte mediators, the best studied of which is MIF. As a result of interaction with MIF, various parameters of macrophage activation such as the rate of protein synthesis were found to be increased. As we have discussed, the rate of macrophage protein synthesis correlated quite well with the suppressor activity of macrophages. Therefore, it is obvious that a number of agents, including products of activated lymphocytes (at least MIF), are capable of augmenting suppressor macrophage activity.

\subsection{The Relationship of Suppressor T Cells to Suppressor Macrophages}

Recent reports of suppressor cells other than macrophages include the specific suppressor T cells of Tada and Taniguchi (1976) and the allotype suppressor T cells described by Herzenberg et al. (1976). In addition, Dutton (1972) has shown that Con A-stimulated T cells can nonspecifically block anti-SRBC responses in Mishell-Dutton culture systems in vitro. Similarly, Peavy and Pierce (1974) have used Con Astimulated $T$ cells to nonspecifically suppress the generation of cytotoxic effector cells to alloantigens in MLC-CML reactions. The mechanism of action in both cases is thought to be a suppression of the proliferative event required for the expression of the effector function (Dutton, 1972; Peavy and Pierce, 1974). However, these studies have not demonstrated whether suppressor $\mathrm{T}$ cells act directly on the responding lymphocytes or via another cell type such as a macrophage. As discussed above, activated macrophages (suppressor macrophages) have been shown to suppress in vitro lymphoproliferative reactions. Gershon (1974), in an exhaustive review of suppressor $\mathrm{T}$ cells, has allowed that the role of macrophages in the actual inhibition of proliferation resulting from suppressor $\mathrm{T}$ cell activity is uncertain. Recently, a suppressor factor has been isolated from Con A-induced suppressor $\mathrm{T}$ cell culture supernatants. This factor suppressed the generation of anti-SRBC responses in in vitro Mishell-Dutton cultures. The factor has been termed 'SIRS' for soluble immune response suppressor (Rich and Pierce, 1974). Analysis of the factor has revealed that it is a glycoprotein secreted by the Con A-stimulated T cell with a molecular weight of 48,000-67,000 daltons (Tadakuma et al. (1976a). SIRS appeared to be distinct from immunoglobulins in that it did not bind to immunoabsorbant columns coated with anti-mouse IgG or IgM (Tadakuma et al., 1976a). More recently Tadakuma et al. (1976b) have demonstrated that SIRS acts not directly on B cells or T cells, but requires macrophages to mediate its effect. Thus far, SIRS has been indistinguishable from MIF (Tadakuma et al., 1976b). Nathan et al. (1973) have reported that MIF is a potent macrophage activator, causing enhanced protein synthesis. As discussed above, Keller (1975b) has shown that macrophage suppressor activity correlated best with the rate of protein synthesis as a measure of activation. Thus, it seems likely that SIRS may generate suppressor macrophages and thereby exert its immunosuppressive effect in vitro. There may not be two separate types of suppressor cells, i.e. suppressor $T$ cells and suppressor macrophages, but rather the actual suppressor cell may always be a macrophage with $\mathrm{T}$ cell dependence for some forms of activation. Folch and Waksman (1974) have shown that normal rat spleens contain suppressor cells which can suppress the proliferative response in mixed leukocyte cultures. The effector cells mediating the suppression were adherent, but cells from donors having undergone adult thymectomy, irradiation and bone marrow reconstitution were inactive. They concluded that the suppressor cell was an adherent suppressor $T$ cell. We have recently confirmed that normal rat spleens contain adherent cells which suppress MLC and CML reactivity (Oehler et al., 1977b). However, we have also shown that the suppressor cells are phagocytic and resistant to treatment with a specific anti-T cell serum and complement. Our data indicate that the final effector cell mediating the suppression is a macrophage. To reconcile our findings with those of Folch and 
Waksman (1974), we have suggested that the activated macrophages in normal rat spleens are a reflection of, and dependent on, $\mathrm{T}$ cell activity in vivo (Oehler et al., 1977c). The early findings of McGregor and Koster (1971) showing a macrophage requirement for the adoptive transfer by immune thoracic duct lymphocytes of immunity to Listeria monocytogenes may be explained in a similar manner. In this case, the immune $T$ cells may have led to the gradual development of activated macrophages with anti-microbial activity.

\subsection{Evidence That Suppressor Macrophages Can Suppress Immune Responses In Vivo}

\subsubsection{Introductory Remarks}

Most of the clear-cut evidence that macrophages can act as suppressor cells comes from in vitro observations. It is rather difficult to directly relate such in vitro findings to the role of these cells in regulating the immune response in vivo. Part of this reflects the general problem of determining the in vivo role of in vitro phenomena. A classical approach in this direction has been to examine the effects of adoptive transfer of cells with a particular function in vitro. However, adoptive transfer of suppressor macrophages seems unlikely to confer a suppressed state on the recipient for at least two reasons. Firstly, highly activated macrophages undoubtedly do not stay highly activated long after transfer. Nathan et al. (1973) showed that macrophages activated by lymphocyte mediators in vitro remained activated only $24-48 \mathrm{hr}$ after removal of the activating agent. Secondly, adoptively transferred, strongly activated macrophages might lodge at the site of inoculation or some other unwanted location and not migrate into the same lymphoid microenvironment as the lymphocytes engaged in the immune response or even into the appropriate lymphoid organs. Local adoptive transfer of macrophages, either admixed with responding lymphocytes or inoculated into the site of the immune response (e.g. draining lymph node), would be expected to overcome these problems. However, little evidence along these lines has been reported. The main approach which has been made to evaluate the in vivo role of macrophages is to administer agents which can stimulate the reticuloendothelial system (RES) and cause the activation and migration of macrophages into the lymphoid and circulatory systems. In addition, various pathological conditions, both experimentally induced and naturally occurring which are associated with RES stimulation, present opportunities to observe the effect of strongly activated macrophages in high cell densities in the proximity of lymphocytes during the generation of an immune response in vivo. There are a number of studies showing a depressed immune response in the presence of either a high macrophage cell density or a highly activated RES. Based in part on the in vitro evidence discussed above, one might predict that immune responses requiring the generation of an expanding clone of antigen-sensitized lymphocytes would be suppressed if sufficient suppressor macrophage activity were present during the proliferative phase of the response. Interpretation of such studies, however, is complicated by the fact that the stimulating agents have in vivo effects other than activation of macrophages, and also that macrophages are involved at many levels of the immune response, both in initiating immune responses, i.e. antigen presentation, antigen processing, prevention of tolerance, and frequently in the final effector phases of the immune response, i.e. delayed hypersensitivity (Scott, 1974), tumor (Remington et al., 1975; Hibbs et al., 1972; Evans and Alexander, 1972) and tissue graft rejection (Evans and Grant, 1972), and protection from certain infectious agents (Gadebusch, 1972). It has been possible to design experiments to take advantage of the fact that macrophage participation in various phases of an immune response to an antigenic challenge do not necessarily occur simultaneously. Shortly after antigenic challenge, macrophages aid in sensitizing lymphocytes. Then, after a lag period which varies from 24-28 hr to several days, depending on the antigen, the lymphoproliferative phase begins, followed by the appearance of the effector phase of the immune 
response, i.e. antibody production, cytotoxic $T$ cell appearance, memory cell distribution and/or macrophage activation. Thus, the lymphoproliferative phase occurs some time after antigen inoculation and continues through the time of the appearance of the effector aspect of the response. To demonstrate suppressive effects of macrophage activation, the optimal time of most intense macrophage activation should be during the proliferative phase, i.e. some time after antigen inoculation and before the appearance of effector cells (plasma cells or cytotoxic $T$ cells). Similar to the kinetics of the immune response, the length of time between injection of a stimulating agent and the appearance of maximal macrophage activation must be taken into account. The kinetics of the appearance of suppressor macrophages in the spleen of experimental animals differs slightly with the particular activating agent used, the dose and the route of administration.

Thus the most convincing evidence that suppressor macrophages can inhibit the generation of an immune response in vivo would come from experiments in which suppressor macrophages and few proliferating lymphocytes have been shown to be in lymphoid organs at the time when one would expect the lymphoproliferative phase of the immune response to be occurring. Ideally, one might then find that upon removal of inactivation of suppressor macrophages, fully immunocompetent lymphocytes remain. In addition, in vivo administration of agents which inactivate macrophages without interfering with their numerous enhancing effects would be expected to reverse the immunosuppression. Such evidence would point to suppressor macrophages as the main or only cause for the suppressed immune response observed in vivo.

In the sections to follow, we shall review the available evidence for in vivo suppression of immune responses by macrophages. In addition, evidence will be reviewed regarding the possibility that some forms of antigenic competition may be due to the appearance of splenic suppressor macrophages.

\subsubsection{Suppression Directly Related to Macrophage Concentration In Vivo}

A simple but still somewhat artificial way to observe the effects of local adoptive transfer of high macrophage concentrations on antigen-triggered lymphocytes in vivo would be to place antigen-primed lymphocytes in a small Millipore chamber with the antigen and a large number of macrophages, and implant the chamber into the peritoneal cavity of a lethally irradiated histocompatible mouse. Measurement of the resultant serum and chamber antibody levels and comparison with levels generated in mice in which similar chambers were implanted without high numbers of macrophages would give some indication of the effect of the extra macrophages.

Using such an experimental design, Perkins and Makinodan (1965) placed SRBCprimed mouse spleen cells in $0.1 \mu \mathrm{m}$ Milliport chambers with SRBC and various numbers of peritoneal exudate cells and implanted them in irradiated mice. As controls, they implanted chambers to which they added either unprimed mouse spleen cells in numbers equal to the primed responding cells plus SRBC or primed responding cells plus SRBC alone. After 9 days, they measured the hemolysin titer in both the chamber fluid and the serum. The antibody titers from mice bearing chambers containing primed spleen cells plus SRBC were very similar to those with primed spleen cells, SRBC and equal numbers of unprimed spleen cells. In contrast, the chamber fluid or sera from mice bearing chambers containing additional PEC sufficient to make up 20-30 per cent of the primed responding cell had markedly depressed titers. No concentration of PEC produced enhanced antibody production and high numbers of PEC completely suppressed the response. To reduce the artificiality of the approach with Millipore chambers, similar experiments were designed in which mice were injected intraperitoneally with glycogen to increase the number and the level of activation of the peritoneal macrophages, or only with saline. Both groups were challenged with SRBC i.p. and the serum hemolysin titers measured every other day for 10 days. At all time points tested, mice pretreated with glycogen 
had lower serum antibody levels compared to the saline-injected controls. The objective of these experiments was to obtain in vivo data to support the notion that macrophages enhanced the SRBC response, but the results which were in the opposite direction indicated that high cell densities of macrophages in the environment of lymphocytes which were stimulated to proliferate and produce antibody could suppress antibody production in vivo. Hoffman (1970), using an in vitro Mishell-Dutton culture system, obtained similar results and, in addition, provided evidence that the suppressive effect of the high concentration of macrophages was mediated through an inhibition of the proliferative phase of the response. He found that the optimal macrophage concentration for an in vitro SRBC response was 2 per cent of the responding spleen cells. Adding purified peritoneal macrophages to a final concentration of 20 per cent of the responding spleen cell population resulted in profound inhibition of the response. Moreover, analysis of the cells in the suppressed cultures revealed greatly decreased blastogenesis and plasma cell formation. He postulated that the high concentration of macrophages inhibited the proliferation of antigensensitive cells, thereby preventing a clonal expansion of cells destined to produce antibody. Alternatively, since $\mathrm{T}$ cells are also required to provide a helper factor for the production of antibody to heterologous erythrocytes, both in vitro and in vivo (reviewed in Oppenheim and Rosenstreich, 1976; Katz and Benacerraf, 1972), the suppressive effect of macrophages could have been mediated through inhibition of the $T$ cell response. However, there is little if any evidence that macrophages can suppress the production and release of factors per se. So this alternative seems unlikely. Moreover, evidence has been presented that suppressor macrophages can inhibit LPS-induced B cell proliferative responses in mice (Kirchner et al., 1974b) and rats (Yoshinaga et al., 1972). Since LPS induces B cell proliferation directly without the aid of accessory cells (Lipsky and Rosenthal, 1976; reviewed by Oppenheim and Rosenstreich, 1976), it would appear that macrophages are capable of suppressing B cell proliferation directly. Thus, it is likely that the suppression by high concentrations of macrophages of antibody production in the above cases was due to inhibition of proliferation of the antigen-sensitized clone of $B$ cells.

\subsubsection{Suppression of Antibody Production In Vivo by a Macrophage-Activating Agent}

Lipopolysaccharide has been shown to activate macrophages (see Section 3.2.4) and in vivo inoculation of this material has been shown to inhibit immune responsiveness (Bradley and Watson, 1964; Franzl and McMaster, 1968). As predicted above, the demonstration of LPS-induced suppression is very dependent on the time of administration of LPS in relation to antigen inoculation. It seems necessary for the LPS to come in contact with macrophages which are closely associated with lymphoid cells prior to exposure to antigen. In other words, if LPS and the antigen (SRBC) were given by the same route, the LPS had to be given $24-48 \mathrm{hr}$ prior to the antigen. Only relatively large doses of LPS induced suppression when given i.p. $24 \mathrm{hr}$ before antigen inoculation into the same area. If LPS was given i.v. $24 \mathrm{hr}$ before antigen i.p., five-fold less endotoxin could totally abrogate the anti-SRBC response (Franzl and McMaster, 1968). Similarly, Bradley and Watson (1964) have shown that a relatively large dose of LPS given to mice at the time of injection of actinophage MSP8 simply delayed the production of neutralizing antibody, whereas daily injections of LPS suppressed the antibody production indefinitely despite continued presence of the phage in the tissues of the animal. Further, hyperimmunized mice with high levels of circulating antibody could be suppressed with daily LPS administration. When the LPS was stopped, the antibody production resumed as indicated by the prompt appearance of high serum levels of neutralizing antibody. The results of these studies indicate that antibody production in mice can be suppressed by an agent which activates macrophages. However, it is possible that the inhibitory effects of LPS are independent of macrophages, since as noted above, LPS can have direct effects on B cells. 

Cells

C. parvum is a powerful RES-activating agent (Halpern et al., 1963) which can induce splenic suppressor macrophages in mice (Kirchner et al., 1975c; Scott, 1972). Similarly, $C$. parvum injection has been shown to suppress some immune responses requiring proliferation in vivo. Immunization procedures which normally conferred a significant amount of protection from tumor challenge were much less effective if instituted 4-5 days after C. parvum injection (Smith and Scott, 1972; Woodruff et al., 1976). The studies of Scott (1972) demonstrated the temporal relationship between $C$. parvum injection and the appearance of suppressor macrophages. Intravenous inoculation of $C$. parvum produced maximal suppression of responsiveness of spleen cells to PHA at day 7, with some persisting inhibition through day 28. This suppression was shown to be mediated by macrophages. Considering this time course for the appearance of suppressor cells in the spleen after $C$. parvum injection, one might predict that immune responses generated in the spleen and dependent upon the rapid expansion of an antigen-sensitized clone of lymphocytes would be suppressed if the proliferative response occurred about 7 days after $C$. parvum injection. Thereafter (for at least 2 weeks) moderate suppression might be observed. Smith and Scott (1972) investigated the protective effects of $C$. parvum injection on challenge of CBA mice with R-1 leukemia cells (a radiation-induced syngeneic leukemia). Inoculation of unimmunized mice with as few as ten tumor cells i.p. resulted in the death of all recipients with 10-15 days. When mice were immunized with a single dose of $1 \times 10^{5}$ heavily irradiated $R-1$ cells 7 days prior to the inoculation of $100 \mathrm{R}-1$ cells i.p., 50 per cent of the mice survived. When $C$. parvum was given 7 days before the immunizing dose of irradiated R-1 cells, 90 per cent of the mice died within 20 days of the injection of non-irradiated R-1 cells. Similarly, Woodruff et al. (1976) have reported that in CBA mice, protection against a syngeneic chemically induced fibrosarcoma by immunization with irradiated tumor cells was decreased by pretreatment with $C$. parvum 5 days before the immunizing dose. Recent studies in our laboratory by Kirchner et al. (1975b) have provided insight into possible mechanisms operative in the experiments described above. C56BL/6 mice injected with Moloney sarcoma virus developed a tumor at the site of inoculation which reached maximum size 14 days after inoculation and regressed completely by 21 days (MSV mouse tumor system). Spleen cells taken from donors after tumor regression could be stimulated to become cytotoxic in vitro by cocultivation with mitomycin C-treated RBL-5 tumor cells, shown to contain relevant antigens (Herberman et al., 1974). To test the effect of $C$. parvum inoculation in this system, mice were given $C$. parvum i.p. 23 days after virus infection, and 7 days later primed spleen cells from these mice were cultured in vitro with RBL-5 to generate cytotoxic effector cells. The cytotoxicity generated with such cells was much lower than that generated with spleen cells from immune mice not treated with $C$. parvum. This effect of $C$. parvum appeared to be mediated by suppressor macrophages, since mixture of immune spleen cells with spleen cells from mice inoculated 8-10 days earlier with $C$. parvum resulted in a marked suppression of generation of cytotoxicity. The suppression by the spleen cells from $C$. parvumtreated mice was dependent on the presence of macrophages but not $T$ cells. Bernstein et al. (1977) have recently shown that the generation of cytotoxic effector cells from non-cytotoxic primed rat spleen cells required the proliferation of a clone of lymphocytes during cocultivation with mitomycin-treated (C58NT)D tumor cells. Similarly, our laboratory has provided evidence that a proliferative response is also required for the generation of cytotoxic effector cells in vitro from non-cytotoxic primed cells in the MSV mouse tumor system (Stiller, Holden and Herberman, unpublished observations). Thus it seems likely that the suppressed cytotoxic response generated in vitro by $C$. parvum-pretreated MSV immune mice was due to the inhibition of the required lymphoproliferative response by the $C$. parvum-induced suppressor macrophages. These observations by no means prove that the interference 
with tumor resistance (Smith and Scott, 1972; Woodruff et al., 1976) was caused by the inhibition of a proliferative response required to generate an immune state, but the similarities between the in vivo observations and the in vitro findings are striking. An important issue is whether the increased numbers of activated macrophages found in the spleens of animals treated with $C$. parvum (or other RES stimulants) can inhibit lymphoproliferative responses sufficiently to suppress in vivo generation of cytotoxic effector cells. Evidence that spleens of $C$. parvum-treated mice can inhibit the proliferation of antigen-stimulated lymphoid cells in vivo has been provided by Howard et al. (1967). They treated $F_{1}$ hybrid mice with i.v. C. parvum 4 days before i.v. injection of $10^{8}$ viable parental lymphoid cells, thus initiating a graft versus host $(\mathrm{GVH})$ reaction in the environment of a highly stimulated reticuloendothelial system. The pretreatment with $C$. parvum protected the majority of the mice from the uniformly fatal GVH reaction which occurred in the untreated control mice. Evidence for the mechanism of action of the protective effect was obtained by examining the spleens of representative mice from each group for proliferating lymphocytes. Twelve days after GVH initiation, the percentage of donor cells in mitosis was $85-90$ per cent in the untreated $F_{1}$ hybrid recipients. In contrast, only $0-5$ per cent of the proliferating cells were of donor origin in the mice pretreated with $C$. parvum. These data show that $C$. parvum induced an environment in the spleens of mice which suppressed rapidly-proliferating alloantigen-stimulated parental lymphoid cells in vivo. It remains to be directly demonstrated that macrophages were in fact responsible for the anti-proliferative effect.

C. parvum and other potent RES stimulators are frequently used as immunotherapeutic agents to increase resistance against tumor growth. However, the observations discussed above indicate that, under some circumstances, these agents may actually interfere with effective anti-tumor immunity and that these immunosuppressive effects may be mediated by suppressor macrophages.

\subsubsection{The Possible Role of Suppressor Macrophages in Antigenic Competition}

The interference with the immune response to an antigen by prior inoculation with high doses of a non-cross-reactive second antigen has been termed antigenic competition. Antigenic competition has been extensively studied and the subject has been thoroughly reviewed recently (Pross and Eidinger, 1974). As suggested by Pross and Eidinger (1974), it seems likely that numerous mechanisms of action are responsible for the various phenomena grouped under the heading of antigenic competition. Since some instances of antigenic competition can actually be shown to be suppressive phenomena and the suppression is at least associated with an inhibition of proliferative response, suppressor macrophages should be considered as one type of mediator of these effects.

Several lines of evidence suggest that some forms of antigenic competition may actually be mediated through a suppressor mechanism rather than direct competition between antigens for responding cells. Sjöberg and Britton (1972) have shown that spleen cells from mice heavily preimmunized with SRBC suppressed the PFU response of normal mouse spleen cells to horse red blood cells (HRBC) when cocultivated in Mishell-Dutton culture systems in the presence of SRBC. Similarly, Thomas et al. (1975) have shown that when spleen cells from mice immunized with ovalbumin (OVA) were added with OVA to Mishell-Dutton cultures with SRBCprimed spleen cells the SRBC-specific PFU response was suppressed compared to cultures in which either the OVA or the OVA immune spleen cells were omitted. Further, Thomas et al. (1975) reported that in suppressed cultures, ${ }^{3} \mathrm{H}-\mathrm{TdR}$ incorporation was depressed compared to nonsuppressed control cultures, indicating that the mechanism of the suppressor effect involved the proliferation rate of the responding cells. Möller (1971a) has presented evidence that DNA synthesis in the spleen of mice subjected to antigenic competition is reduced compared to normal controls. When mice were preimmunized by two injections of HRBC and then irradiated with 
$900 \mathrm{r}$ before receiving normal spleen cells in adoptive transfer, the rate of DNA synthesis in the spleen as determined by ${ }^{125} \mathrm{IUdR}$ incorporation in vivo was suppressed by $40-50$ per cent when compared to unimmunized but otherwise similarly treated control mice. Whether $\mathrm{T}$ cells or $\mathrm{B}$ cells were preferentially suppressed in these systems was not tested. However, there is evidence that the suppressive effect can be observed on either population. Although it is generally accepted that the induction of antigenic competition requires injection of a T-dependent antigen (reviewed in Pross and Eidinger, 1974), the antibody response to $\mathrm{T}$-independent antigens was shown to be susceptible to suppression (Sjöberg and Britton, 1972), suggesting that B cells could be suppressed directly. On the other hand, Bash et al. (1976) have shown that spleen cells from rats injected $24 \mathrm{hr}$ earlier with large doses of OVA i.v. responded poorly to PHA compared to normal controls, and when mixed with normal spleen cells, these cells were highly suppressive. The experiments showed that the suppressive effect on proliferation in vitro could also affect $T$ cells. The apparent lack of specificity of the suppressor effect is consistent with the nonspecific nature of suppressor macrophage activity (reviewed by Kirchner et al., 1976). Bash et al. (1976) have shown that the suppressor cell activated by injection of large doses of OVA is adherent and somewhat sensitive to carrageenan [a specific macrophage toxin (Lake et al., 1971)]. However, since low doses of cyclophosphamide given i.p. at the time of antigen administration in vivo also abrogated the suppressor effect, the authors concluded that $T$ cells and macrophages acted synergistically to be suppressive. Thomas et al. (1975) have shown that the suppression of AFC production in vitro by OVA immune mouse spleen cells cultured in the presence of OVA was mediated by a soluble suppressor factor produced by $T$ cells. The characteristics of the factor are not unlike those of 'SIRS', another soluble suppressor described by Rich and Pierce (1974) and characterized by Tadakuma et al. (1976). SIRS, as discussed above (Section 3.3), is a product of Con A-stimulated T cells which can nonspecifically suppress AFC production to heterologous erythrocytes in vitro. The mechanism of action has to some extent been elucidated in that the target cell has been shown to be a macrophage in the responding cell population (Tadakuma et al., 1976). Thus, the role of suppressor macrophages in the experiments reported by Thomas et al. (1975) would seem to require further investigation.

In summary, although the mechanisms for antigenic competition are largely unknown and may be quite heterogeneous, in the instances in which suppression of proliferation is associated with the depressed response, it seems likely that suppressor macrophages activated by antigen-stimulated $\mathrm{T}$ cells or their products play a role.

\subsubsection{The Role of Macrophages in Immunosuppression Associated with Graft Versus Host Disease}

In mice, antibody responses to SRBC have been shown to be greatly suppressed in vivo after induction of chronic GVH disease (Blanden, 1969; Möller, 1971b). Blanden (1969) also has shown that in mice undergoing mild chronic GVH, immunization with KLH in complete Freund's adjuvant was virtually ineffective, as indicated by a greatly depressed immediate hypersensitivity reaction upon challenge with antigen. Similarly, PFU responses generated in vivo to $\mathrm{T}$-independent antigens have also been shown to be suppressed in mice undergoing chronic GVH. In contrast to the decreased humoral response to the various types of antigens (cellular, soluble, $T$-dependent and $\mathrm{T}$-independent), the resistance of such mice to infection with Listeria monocytogenes was significantly increased (Blanden, 1969). Such increased resistance has frequently been associated with elevated levels of macrophage activity (McGregor and Koster, 1971). As discussed earlier, states of increased macrophage activation in vivo have occasionally been associated with immunosuppressive effects. One might therefore predict that normal syngeneic lymphoid cells adoptively transferred into irradiated animals undergoing chronic GVH disease would be immunosuppressed. Möller (1971b) has shown that this is indeed the case. He found that 
both primed and normal spleen cells when adoptively transferred into irradiated $F_{1}$ mice undergoing chronic GVH disease had strongly suppressed antibody responses to i.v. SRBC when compared to irradiated and adoptively transferred but otherwise normal $F_{1}$ control recipients. Byfield et al. (1973) showed that viable parental $T$ cells were required in the cells injected to induce GVH disease-related suppression of the response to SIII. However, certain aspects of their findings led them to postulate that macrophages, perhaps activated in response to the alloantigen-stimulated parental $T$ cells, in fact directly mediated the suppressor effect. This was supported by the findings of Sjöberg $(1971,1972)$. He has shown that spleens taken from $F_{1}$ hybrid donors 1 week after induction of GVH disease (GVH spleen cells) were essentially unresponsive to SRBC in Mishell-Dutton cultures. Moreover, when GVH spleen cells were added to normal or primed $F_{1}$ or parental spleen cells with $S R B C$, the response was strongly suppressed compared to $F_{1}$ or parental spleen cells cultured with SRBC alone (Sjöberg, 1971). The media from suppressed cultures could support strong anti-SRBC responses of normal spleen cells, indicating the suppression was not due to media exhaustion or a stable soluble factor. Pretreatment of the GVH spleen cells with anti-theta and complement before mixing with normal cells did not abrogate the suppressor activity. Depletion of phagocytes from the GVH spleen cells with iron and magnet treatment did abrogate the suppressor effect, indicating that the suppressor cell was a macrophage (Sjöberg, 1972). Thus, taken together, the findings of Byfield et al. (1973) and Sjöberg $(1971,1972)$ provided further evidence that in some cases, suppressor macrophages can be generated in response to activated $\mathrm{T}$ cells.

In addition to the suppressed humoral responses observed in chronic GVH disease, cellular reactions have also been shown to be suppressed. Lapp and Möller (1969) have shown that skin grafts from allogeneic mice survived significantly longer when grafted to unrelated $F_{1}$ hybrid recipients undergoing $G V H$ disease. Both primary and secondary set rejection times could be delayed. However, the mechanism for this immune suppression has not been extensively studied.

Chronic GVH disease then appears to be another example of a situation in which suppressed immune responses can be demonstrated in vivo and in which the suppression of the responses in vitro can be shown to be mediated by macrophages. Further, as in the case of antigenic competition, it seems likely that the suppressor macrophages are $\mathrm{T}$ cell-dependent.

\subsubsection{The Role of Macrophages in Immunosuppression Associated with Cancer and Other Pathological Conditions}

Cancer, miliary tuberculosis, sarcoidosis, lepromatous leprosy and severe viral illnesses are among those diseases associated with depressed humoral and cellular responsiveness (Hersh et al., 1973; Smith, 1972; Turk and Waters, 1971). Patients with advanced cancer have long been known to have suppressed delayed hypersensitivity responses when skin tested with tuberculin (Renaud, 1926), mumps (Logan, 1956; Lamb et al., 1962) and other microbial antigens (Logan, 1956; Lamb et al., 1962; Solowey and Rappaport, 1965). In addition, there is evidence that some cancer patients have a delayed rejection of allogeneic grafts of skin and tumor cells (Gardner and Preston, 1962). Lee et al. (1970) were able to demonstrate significant impairment of the ability of non-lymphoid cancer patients to generate serum levels of antibody to flagellin from Salmonella adelaide when compared to the response of age-matched, hospitalized patients with diseases thought not to have immunosuppressive effects. Whether such depressed cellular and humoral immune responses precede and perhaps play an etiologic role in these conditions, or are a result of them is uncertain. In the case of cancer patients, however, the demonstration of an anergic state is frequently associated with a poor prognosis (reviewed by Hersh et al., 1973). Thus, insight into the mechanisms resulting in such disease-related immunosuppression could be helpful in developing a more sophisticated approach to the medical management of this group of patients.

Patients with multiple myeloma frequently have suppressed serum levels of normal 
immunoglobulin, respond poorly to antigenic stimulation, and are highly susceptible to infection (Fahey et al., 1963; Broder et al., 1975). Broder et al. (1975) have shown that PBL from multiple myeloma patients cultured in vitro with pokeweed mitogen (PWM) synthesized significantly less immunoglobulin than PBL from normal volunteers under similar conditions. In addition, in many cases, PBL from multiple myeloma patients, when added to normal PBL, suppressed their immunoglobulin synthesis in response to PWM. When phagocytic mononuclear cells were depleted from the PBL of the multiple myeloma patients, the ability to suppress normal PBL immunoglobulin synthesis in response to PWM was largely abrogated. Moreover, the response of PBLs of a myeloma patient to PWM was greatly improved by removal of phagocytic cells. PWM induces a blastogenic response in both $T$ cells and $B$ cells (reviewed by Oppenheim and Rosenstreich, 1976) and X-irradiation of human B cells prior to culture with PWM prevents the appearance of immunoglobulin in the media (T. Waldmann, personal communication). These findings suggest that monocytes in the PBL of some myeloma patients can suppress the proliferation and immunoglobulin production of human B cells in vitro. Similarly, in a rodent plasmacytoma model (Krakauer et al., 1976), ascitic fluid from tumor-bearing hypogammaglobulinemic mice was found to contain a low molecular weight trypsin-sensitive factor which suppressed PWM-induced immunoglobulin synthesis by normal mouse spleen cells or human PBL. When the ascites from such mice was depleted of phagocytic cells, the suppressor factor could no longer be demonstrated. Similarly, Kolb et al. (1977) have found that macrophages in the spleens taken from hypogammaglobulinemic mice bearing large plasmacytomas suppressed the PFC response of normal spleen cells to SRBC in a Mishell-Dutton culture system when added in as third parties. These studies taken together provide evidence that in both mice and humans suppressor macrophages and/or their products can suppress the production of immunoglobulin by B cells from normal or tumor-bearing individuals in vitro. These findings are consistent with the findings of Kirchner et al. (1976) and others (Yoshinaga et al., 1972) that in animal systems, B cell mitogen-induced proliferative responses can be suppressed by suppressor macrophages.

Allogeneic skin graft survival was prolonged on some patients bearing malignant neoplasms (Gardner and Preston, 1962). A number of in vitro observations of suppressed MLC responses using cells from cancer patients have provided evidence that suppressor macrophages may be involved in this form of immunosuppression also. Berlinger et al. (1976) have compared MLC reactivity of PBL from patients with solid, non-lymphoid malignancies to the reactivity of PBL from normal donors. They were able to identify a group of cancer patients in whom MLC reactivity was consistently depressed compared to normal controls. When the PBL with suppressed responsiveness were passed through a Sephadex G-10 column which selectively depleted monocytes, the MLC reactivity was improved in all cases which were suppressed. When PBL from normal donors were similarly filtered, no such effect was seen. Our laboratory (Jerrells, Dean and Herberman, unpublished observations) has confirmed that the lymphoproliferative responses of some cancer patients to mitogens or to allogeneic PBL could be significantly increased by passage of their PBL over Sephadex G-10 columns. Furthermore, the addition of mitomycin C-treated PBL from these patients to cultures of normal PBL could significantly inhibit proliferative responses to $T$ cell mitogens. However, this mechanism does not appear to account for the depressed lymphoproliferative responses of all such patients, since in some cases, the responses remained depressed after removal of adherent cells. Twomey et al. (1975) have shown that PBL from patients with Hodgkin's disease stimulated normal PBL poorly in MLCs. When adherent cells were depleted from the patients' cells used as stimulators, strong MLC responses were observed. They could show that the suppressor cell was radioresistant and required protein synthesis to be suppressive, but their failure to show the cell was phagocytic using a 'modified technique' led them to postulate that the suppressor cell was a lymphocyte similar to that observed in normal rat spleen cells by Folch and Waksman (1974). As discussed 
earlier, recent evidence suggests that the cells described by Folch and Waksman were actually $T$ cell-dependent suppressor macrophages. Thus it is possible that the findings of Twomey et al. (1975) may also support the notion that suppressor macrophages from PBL of cancer patients can suppress the proliferative phase of the response to alloantigens in vitro.

Studies in experimental animal tumor systems have provided a firm basis for the role of suppressor macrophages in the immunodepression of tumor-bearing individuals. Our laboratory (Fernbach et al., 1976b) has shown that spleen cells from mice bearing MSV-induced tumors responded poorly in MLC and CML reactions. As described earlier, these depressed responses were shown to be mediated by suppressor macrophages. Veit and Feldman (1976a) have studied a rat tumor model in which they found suppressed MLC responsiveness with spleen cells from tumorbearing rats. Extensive cell characterization procedures identified the suppressor cells as macrophages (Veit and Feldman, 1976b). Eggers and Wunderlich (1975) have provided evidence that spleen cells from mice bearing a methylcholanthrene-induced tumor also contained suppressor macrophages which suppressed the in vitro generation of cytotoxic effector cells to alloantigens. In contrast, Fujimoto et al. (1976a) have reported that when mice bearing methylcholanthrene-induced tumors served as donors of thymocytes to be adoptively transferred to syngeneic mice just prior to tumor inoculation, the rate of eventual tumor regression was slowed. Since thymocytes treated with anti-theta and complement had no such effect, Fujimoto et al. (1976b) concluded that the suppressor cells were T cells. However, since survival rates of the 'suppressed' and the nonsuppressed groups were identical, despite significant $(p<0.001)$ differences in the rate of tumor regression, it is difficult to draw firm conclusions from these experiments. Further, since all of the experiments were performed in vivo, the mechanism of the enhanced tumor growth, i.e. whether mediated through suppressor macrophages and acting on the immune response to the tumor or by direct enhancement of the growth of the tumor, would seem to be an open question.

Thus, suppressed $\mathrm{T}$ cell responses to alloantigens have been demonstrated in a variety of tumor systems. In mice, rats and humans, suppressed MLC responses have been shown to be due to cells which have been characterized as monocytes or macrophages by a number of criteria. Spontaneously occurring tumors as well as tumors induced by virus infection and carcinogen inoculation have been shown to induce suppressor monocytes or macrophages in the PBL of humans or spleen of mice and rats which can suppress reactivity to alloantigens. Therefore, these in vitro findings provide at least one possible explanation for the observations that allogeneic skin graft survival is prolonged in cancer patients. It would seem that further investigations designed to clearly define the role of suppressor macrophages in suppression of immune responses to alloantigens in vivo are indicated.

In addition to cancer, certain infectious diseases are known to be associated with suppression of immune responses. Generally, the degree of immunosuppression has correlated with the severity of the disease. The cause and effect relationship between the phenomena is an important question to be answered. Leprosy, a human disease caused by infection with Mycobacterium leprae, has provided insight into the correlation of immunosuppression with the severity of disease. Turk and Waters (1971) studied histological sections of lymph nodes taken from patients with leprosy varying in severity from tuberculoid leprosy (with the best prognosis), through borderline leprosy (an intermediate stage), to lepromatous leprosy (disseminated disease). Tuberculoid leprosy was associated either with a completely normal appearing lymph node or with nodes demonstrating a lymphocytosis of the paracortical areas [generally considered to be thymus-dependent (Parrot and Desousa, 1971)]. Occasionally, lymphoblasts were noted in the paracortical areas, indicating the presence of ongoing lymphoproliferative responses. These patients responded well to intradermal lepromin testing and could be sensitized to dinitrochlorobenzene (DNCB). Lymph nodes from patients with leprosy of intermediate severity showed an infiltration of the paracorti- 
cal regions with epithelioid-like cells which remained distinctly separate from the lymphocytes. These patients responded to intradermal lepromin albeit poorly, but could be sensitized to DNCB. In lepromatous leprosy, paracortical areas of lymph nodes were heavily infiltrated with foamy histiocytes and the germinal centers manifested a hyperplastic plasmacytosis. These patients had a negative lepromin test and usually could not be sensitized to DNCB. Thus, this study provides in vivo morphological evidence for an association between severity of immunosuppression and macrophage infiltration of lymphoid tissues.

\subsection{The Differential Effect of Macrophages on Normal Versus Neoplastic Cells}

Keller compared the effects of activated macrophages on normal versus neoplastic cells and found that, although both cell types undergo inhibition of proliferation, only neoplastic cells were killed (Keller, 1974a, 1976). Evidence supporting the notion that only neoplastic cells are killed by macrophages, thus establishing the concept of nonspecific but 'selective' macrophage-mediated cytotoxicity, has been provided by several laboratories (Currie and Basham, 1975; Cleveland et al., 1974; Hibbs, 1973; Holterman et al., 1973; Hibbs et al., 1973; Piessens et al., 1975). All of these studies, however, measured target cell lysis rather than target cell proliferation. Our laboratory (Kirchner et al., 1974a, b, 1975) has noted on several occasions that the suppressive effect of macrophages on lymphocytes was not observed unless the lymphocytes were proliferating rapidly (i.e. stimulated by mitogens, tumor antigens, or alloantigens, etc.). One might therefore speculate that some property of transformed cells which is shared by proliferating lymphocytes but not by resting lymphocytes provides the basis by which macrophages exert their cytolytic and/or cytostatic effect. Evidence suggesting that rapidly proliferating cells are more susceptible to lysis by macrophages than resting cells has been provided by Holterman et al. (1975). They have shown that rat embryo fibroblasts are susceptible to cytolytic effects only during early passages in tissue culture, when their proliferation rate is high. They hypothesized that neoplastic cells may have certain membrane properties in common with rapidly proliferating embryonic cells of early passage in vitro which are subsequently lost through the process of differentiation. Fox et al. (1971) have provided evidence that mild proteolytic treatment of normal mouse fibroblasts maintained in vitro (3T3) resulted in the appearance of certain agglutinin receptors on the surface of the cell membrane which could always be demonstrated on the membrane of polyoma virus transformed mouse fibroblasts (Py3T3). The expression of the agglutinin receptors on the $3 \mathrm{~T} 3$ cells was associated with an increased rate of proliferation and a loss of contact inhibition. The effect was transient, however, and when the proliferation rate returned to normal, the agglutinin receptors were no longer demonstrable. Although these studies were done with fibroblasts and not with lymphoid cells, they at least support the notion that rapidly proliferating cells may express receptors or membrane properties normally expressed 'selectively' on continually proliferating (transformed) cells. Shinitzky and Inbar (1974) have provided evidence that the microviscosity of the surface membrane lipid layer of normal lymphocytes and malignant lymphoma cells can be associated with the growth characteristics of the cells, and that by altering the microviscosity of the membrane with lecithin-cholesterol (1:1) liposomes, one can predictably modify the growth characteristics of the cells. These observations further emphasize the possibility that normal cells may transiently acquire membrane characteristics of transformed cells during blastogenesis. Thus, if the mechanism by which macrophages lyse transformed cells is the same as that mediating cytostasis of both cell types, the ability of lymphocytes to cover or fail to express some membrane property when their proliferation is inhibited could account for the findings that macrophages have cytostatic effects on both cell types but lyse only cells which are transformed. Another entirely possible explanation for the findings is that the effector cells involved in the cytolysis are not macrophages at all but instead are natural killer (NK) cells as recently described by Herberman et 
al. (1975). Recently Herberman et al. (1977) have shown that many agents with well-known RES activating effects strongly boost NK cell activity when administered to mice, and that the broad specificity of the cytolytic activity is directed primarily toward tumor cells. Similarly, Wolf et al. (1976) observed that i.p. injection of BCG caused the appearance of increased cytolytic activity by PEC and that most, if not all, of this activity was mediated by NK cells. Our laboratory is currently investigating the possibility that at least some of the selective cytolytic effects of PEC previously attributed to macrophages may be mediated by highly active NK cells.

\section{CONCLUDING REMARKS}

In this review we have discussed some of the evidence that macrophages provide both enhancing and suppressive effects on immune responses. The enhancing effects of macrophages might be grouped into three broad categories: prevention of tolerance, antigen presentation and enhancing factor production. In the case of subcellular protein antigens, macrophages phagocytize and break down much of the antigen, thus helping to prevent a prolonged interaction of $B$ cells with high concentrations of free soluble antigen, in the absence of a second signal to produce antibody, which would be likely to result in a state of B cell tolerance. Some of the antigen, however, is not broken down by macrophages, but instead is expressed on the cell surface in a highly immunogenic form. Recent evidence suggests that one form taken by such antigen is that of a complex with the MHC antigens on the surface of the macrophage. As such, at least $\mathrm{T}$ cells can be primed or triggered with the resultant generation of helper $T$ cells to provide a second signal to $B$ cells for antibody production and/or a clone of highly reactive memory $T$ cells which are then available to mediate a vigorous secondary response when presented with the same antigen in complex with the same MHC determinant on the surface of a macrophage. In addition to presentation of soluble antigens to $T$ cells, there is a wealth of information suggesting that macrophages produce factors which can enhance the response of $\mathrm{T}$ cells to mitogens as well as to cellular antigens such as alloantigens in MLC or antigens on the surface of heterologous erythrocytes. More detailed discussion of these factors can be found elsewhere in this series. Less is known about the macrophage- $B$ cell interaction. There are a number of reports showing that macrophages can stimulate B cells directly to proliferate and produce antibody. In addition, there is some evidence that macrophages may play a vital role in mediating $\mathrm{T}$ cell-B cell collaboration. Further investigations are needed to clarify these issues.

On the other hand, we have presented evidence that macrophages, if in sufficient quantity or if sufficiently activated, can suppress immune responses which are dependent on the expansion of a clone of sensitized lymphocytes. Suppression of $T$ cell proliferation by-suppressor macrophages in vitro can be correlated with evidence obtained in vivo indicating that when macrophages were strongly activated during the time when a lymphocyte proliferative response should have occurred, the resultant immune state was frequently depressed. Similarly, since suppressor macrophages could also suppress B cell proliferative responses in vitro, it is not surprising that antibody responses requiring $B$ cell proliferation were frequently suppressed in cases where the RES was highly activated such as in chronic graft versus host disease, some cases of antigenic competition and in the presence of a rapidly growing malignant tumor.

The suppressive effect of macrophages would seem to be important for several reasons. We have discussed evidence that suppressor macrophages could be induced by lymphocyte mediators. The best studied mediator apparently capable of inducing suppressor macrophages is MIF. In fact, as discussed, it seems likely that many if not all suppressor $T$ cells may liberate factors which mediate the suppressor effect through macrophages. This then would appear to represent a mechanism by which a clonal expansion of sensitized lymphocytes could be slowed or stopped by a product of lymphocyte activation. Since 2 or 3 days are required to activate macrophages with 
lymphocyte mediators (see Section 3.2.4.), such a mechanism would not prevent the appearance of a significant number of effector cells and memory cells but could serve to limit their continued, excessive production. Such negative feedback systems have been described for many regulatory mechanisms in mammalian physiology. As we have discussed, suppressor macrophages have little or no suppressor effect on cytotoxic $T$ cells or other effector cells which do not proliferate. Thus, established immune responses would not be affected through this mechanism.

In addition, macrophages can be activated to become suppressive by agents which may operate through mechanisms independent of lymphocytes. Agents or conditions which activate the RES, including the growth of many tumors, have frequently resulted in the appearance of splenic suppressor macrophages. Although in this review we have concentrated on reports of immunosuppression associated with administration of RES activators (C. parvum and BCG), in fact, these agents are generally thought of as immunopotentiators. However, a problem with the use of such agents is that the immunopotentiating effects are seen inconsistently and, frequently, immunosuppression is seen instead. The effects of these agents on the immune response in vivo are undoubtedly complex. When used correctly, RES stimulators may eventually prove very useful for immunotherapy. However, when immunosuppression occurs instead of immunopotentiation, it seems likely that suppressor macrophages play a role in the suppression. In the case of RES activation in response to tumor growth, an interesting situation arises. Although perhaps an appropriate response to the tumor, if the RES activation cannot control the growing neoplasm by direct cytostatic effects on the tumor cells, it is entirely possible that the resulting abundance of suppressor macrophages may play a role in the immunosuppressed state frequently observed in cancer patients. There are undoubtedly many ways in which tumors can cause immunosuppression. One way, however, might be through a mechanism by which tumor cells or tumor cell products lead to an activated RES which suppresses immune responses requiring lymphocyte proliferation. In this case, however, unlike the response of local macrophages to mediators from sensitized, activated, proliferating lymphocytes, the RES stimulus from the tumor might be more diffuse, involving a significant proportion of the lymphoid cells. One would predict that this would result in a prolonged, nonspecific state of immunosuppression.

Finally, we have briefly discussed the apparently reproducible observations that, although the cytostatic effects of macrophages on rapidly dividing lymphocytes and transformed cells seem highly correlative, the 'lytic effects of macrophages' are directed selectively toward cells that are neoplastic. Assuming that macrophages are indeed the effector cells, we have suggested that the basic recognition process leading to the cytostatic and the cytolytic events are similar, and that the selective lysis of neoplastic cells reflects the inability of tumor cells to modulate certain surface receptors shared by normal lymphocytes only during blastogenesis.

In summary, macrophages seem to be involved in almost every phase of the immune response. They can both enhance and suppress lymphocyte responses, and most lymphocyte responses require the presence of macrophages for any of a number of reasons to mount any response at all. The observations that suppressor $\mathrm{T}$ cells may mediate some if not all of their suppressor effects through suppressor macrophages help to explain what appeared to be a dual suppressor mechanism triggered by similar stimuli but mediated by different effector cells. The evidence discussed in this review supports the concept that macrophages play a central role in regulating some aspects of the immune response. Hopefully, further investigations of the immunobiology of macrophages will enable careful therapeutic intervention via this natural regulatory mechanism.

Acknowledgments - The authors wish to gratefully acknowledge many stimulating discussions with Dr. Holger Kirchner concerning the suppressive effects of macrophages. In addition, we thank Drs Santo Landolfo, Angela Santoni, and James Braatz for knowledgeable suggestions and helpful comments.

Finally, one of us thanks Laurie for being patient and understanding. 


\section{REFERENCES}

Adlam, C., Reid, D. E. and Torkington, P. (1975) The nature of the active principle of Corynebacterium parvum. In: Corynebacterium Parvum; Applications in Experimental and Clinical Oncology pp. 35-39, HalPERn, B. (ed.). Plenum Press, New York, London.

Allison, A. C. and Davies, P. (1975) Increased biochemical and biological activities of mononuclear phagocytes exposed to various stimuli, with special reference to secretion of lysosomai enzymes. In: Mononuclear Phagocytes in Immunity, Infection and Pathology pp. 487-506, FURTH, R. V. (ed.). Blackwell Scientific Publications, Oxford, London.

Allison, A. C., Hammington, J. S. and Birbeck, M. (1966) An examination of the cytotoxic effects of silica on macrophages. J. exp. Med. 124: 141-153.

ARGYRIS, B. F. (1968) Role of macrophages in immunological maturation J. exp. Med. 128: 459-468.

Bach, F. H., Alter, B. J., Solliday, S., Zoschke, D. C. and JaNIS, M. (1970) Lymphocyte reactivity in vitro. II. Soluble reconstituting factor permitting response of purified lymphocytes. Cell. Immun. 1: $219-225$.

Bash, J. A., Singer, A. M. and Waksman, B. H. (1976) The suppressive effect on the proliferative responses of rat $\mathrm{T}$ cells in vitro. II. Abrogation of antigen-induced suppression by selective cytotoxic agents. J. Immun. 116: 1350-1353.

Bechtol, K. B., Freed, J. H., Herzenberg, L. A. and McDevitt, H. (1974) Genetic control of the antibody response to poly-L (Tyr, Glu)-poly-D, L-Ala-poly-L-Lys in C3H-CWB tetraparental mice. J. exp. Med. 140:1660-1675.

BeCHTOL, K. B. and MCDEvitT, H. O. (1976) Antibody response of $\mathrm{C} 3 \mathrm{H} \leftrightarrow(\mathrm{CKB} \times \mathrm{CWB}) \mathrm{F}_{1}$ tetraparental mice to poly-L (Tyr, Glu)-poly-D, L-Ala-poly-L-Lys immunization. J. exp. Med. 144: 123-144.

BENACERRAF, B. and MCDEvITT, H. O. (1972) Histocompatibility-linked immune response genes. Science 175: $272-274$.

BENNET, B. (1966) Isolation and cultivation in vitro of macrophages from various sources in the mouse. Am. J. Path. 48: 165-181.

BERLINGER, N. T., LOPEZ, C. and GOOD, R. A. (1976) Facilitation or attenuation of mixed leukocyte culture responsiveness by adherent cells. Nature 260: 145-146.

BERNSTEIN, I., COHEN, E. and WRIGHT, P. (1977) Relationship of cellular proliferation and the generation of cytotoxic cells in an in vitro secondary immune response to syngeneic rat lymphoma cells. J. Immun. 118: $1090-1094$

Bevan, M., Epstein, R. and COHN, M. (1974) The effect of 2-mercaptoethanol on murine mixed lymphocyte cultures. J. exp. Med. 139: 1025-1030.

BLAESE, M. R. (1975) Macrophages and the development of immunocompetence. In: The Phagocytic Cell in Host Resistance, 1975 pp. 309-317, Bellanti, J. A. and Dayton, D. H. (eds.). Raven Press, New York.

BlaEse, M. R., LAWRENCE, C. E. and Poplack, D. G. (1977) A critique of techniques of macrophagemonocyte depletion in studies of human peripheral blood mononuclear leukocyte (MNL) function. In: Proceedings of the Eleventh Leukocyte Culture Conference, 1977. LUCAS, D. (ed.). Academic Press, New York (in press).

Blaese, M. R., Oppenheim, J. J., Seeger, R. C. and Waldman, T. A. (1972) Lymphocyte-macrophage interaction in antigen induced in vitro lymphocyte transformation in patients with the Wiskott-Aldrich syndrome and other diseases with anergy. Cell. Immun. 4: 228-242.

BLANDEN, R. V. (1969) Increased antibacterial resistance and immunodepression during graft-versus-host reactions in mice. Transplantation 7: 484-497.

Bloom, B. R. and David, J. R. (eds.) (1976) In Vitro Methods in Cell-Mediated and Tumor Immunity Academic Press, New York.

Bodel, P. T., Nichols, B. A. and Bainton, D. F. (1977) Appearance of peroxidase reactivity within the rough endoplasmic reticulum of blood monocytes after surface adherence. J. exp. Med. 145: 264-274.

Bomford, R. and OlivotTo, M. (1975) Inhibition by Corynebacterium parvum of lung-nodule formation by intravenously injected fibrosarcoma cells. In: Corynebacterium parvum: Application in Experimental and Clinical Oncology pp. 268-275, HaLPERN, B. (ed.). Plenum Press, New York.

Boumsell, L. and Meltzer, M. S. (1975) Mouse mononuclear cell chemotaxis. I. Differential response of monocytes and macrophages. J. Immun. 115: 1746-1748.

BRadley, S. G. and WATSON, D. W. (1964) Suppression by endotoxin of the immune response to actinophage in the mouse (29640). Proc. Soc. exp. Biol. Med. 117: 570-574.

Broder, S., Humphrey, R., Dur, M., Blackman, Meade, B., Goldman, C., Strober, W. and Waldmann, T. (1975) Impaired synthesis of polyclonal (non-paraprotein) immunoglobulins by circulating lymphocytes from patients with multiple myeloma. New Engl. J. Med. 293: 887-892.

Byfield, P., Christie, G. H. and Howard, J. G. (1973) Alternative potentiating and inhibitory effects of GVH reaction on formation of antibodies against a thymus-independent polysaccharide (SIII). $J$. Immun. 111: 72-81.

Calderon, J., Kiely, J.-M., Lefko, J. L. and Unanue, E. R. (1975) The modulation of lymphocyte functions by molecules secreted by macrophages. I. Description and partial biochemical analysis. $J$. exp. Med. 142: 151-164.

CALDERON, J. and UNANUE, E. (1974) The release of antigen molecules from macrophages: characterization of the phenomena. J. Immun. 122: 1804-1814.

Calderon, J., Williams, R. T. and Unanue, E. R. (1974) An inhibitor of cell proliferation released by cultures of macrophages. Proc. natn. Acad. Sci. USA 71: 4273-4277.

CAlKINS, C. E. and Golub, E. S. (1972) Direct demonstration of lymphocyte-macrophage cooperation in the absence of physical contact between the two cell types. Cell. Immun. 5: 579-586.

CANTOR, H. and JANDINSKI, J. (1974) The relationship of cell division to the generation of cytotoxic activity in mixed lymphocyte culture. J. exp. Med. 140: 1712-1716

CARTER, B. G. and RECTOR, E. S. (1972) The generation of antigen-sensitive cells in the newborn mouse. $J$. Immun. 109: 1345-1351. 
CHEN, C. and HIRSCH, J. G. (1975) The effects of certain thiols on mouse lymphoid cell survival and on antibody production in vitro. In: Mononuclear Phagocytes in Immunity, Infection and Pathology pp. 765-774, Van FurTh, R. (ed.). Blackwell Scientific Publications, London.

CHEN, C. and HIRSCH, J. (1972) The effects of mercaptoethanol and of peritoneal macrophages on the antibody-forming capacity of nonadherent mouse spleen cells in vitro. J. exp. Med. 136: 604-617.

Chused, T. M., KASSAN, S. S. and Mosier, D. E. (1976) Macrophage requirement for the in vitro response to TNP Ficoll: a thymic independent antigen. J. Immun. 116: 1579-1581.

Cleveland, R. P., Meltzer, M. S. and Zbar, B. (1974) Tumor cytotoxicity in vitro by macrophages from mice infected with Mycobacterium bovis strain BCG. J. natn. Cancer Inst. 52: 1887-1895.

Click, R. E., BENCK, L. and ALTER, B. J. (1972) Immune responses in vitro. I. Culture conditions for antibody synthesis. Cell. Immun. 3: 264-276.

Cline, M. J. and Sumner, M. A. (1972) Bone marrow macrophage precursors. I. Some functional characteristics of the early cells of the mouse macrophage series. Blood 40: 62-64.

Cline, M. J. and SwetT, V. C. (1968) The interaction of human monocytes and lymphocytes. J. exp. Med. 128: 1309-1325.

COSEnZA, H., LESERMAN, L. and Rowley, D. (1971) The third cell type required for the immune response of spleen cells in vitro. J. Immun. 107: 414-421.

CURRIE, G. A. and BASHAM, C. (1975) Activated macrophages release a factor which lyses malignant cells but not normal cells. J. exp. Med. 142: 1600-1605.

David, J. R. (1975) Macrophage activation by lymphocyte mediators. Fedn Proc. 34: 1730-1742.

Dean, J. H., Kibrite, A., Jerrells, T. R. and Herberman, R. B. (1977) Technical considerations for the separation of human peripheral blood lymphocyte subpopulations by rosetting with sheep erythrocyte. In: Proceedings of the Eleventh Leukocyte Culture Conference, pp. 583-586, LuCAS, D. (ed.). Academic Press, New York.

DutTon, R. W. (1972) Inhibitory and stimulatory effects of Concanavalin A on the response of mouse spleen cell suspensions to antigen. J. exp. Med. 136: 1445-1460

Edelson, P. J. and COHN, Z. A. (1976) Purification and culture of monocytes and macrophages. In: In Vitro Methods in Cell-Mediated and Tumor Immunity BLOOM, R. and DAVID, J. (eds.). Academic Press, New York.

EgGers, A. E. and Wunderlich, J. R. (1975) Suppressor cells in tumor-bearing mice capable of nonspecific blocking of in vitro immunization against transplant antigens. J. Immun. 114: 1554-1556.

Ellner, J. J. and Rosenthal, A. S. (1975) Quantitative and immunologic aspects of the handling of 2,4-dinitrophenyl guinea pig albumin in macrophages. J. Immun. 114: 1563-1569.

Epstein, L. B., Cline, M. J. and Merigan, T. C. (1971a) PPD-stimulated interferon: in vitro macrophagelymphocyte interaction in the production of a mediator of cellular immunity. Cell. Immun. 2: 602-613.

Epstein, L. B., Cline, M. J. and Merigan, T. C. (1971b) The interaction of human macrophages and lymphocytes in the PHA-stimulated production of interferon. J. natn. Cancer Inst. 50: 744-746.

ERB, P. and FELDMANN, M. (1975a) The role of macrophages in the generation of T-helper cells. III. Influence of macrophage-derived factors in helper cell induction. Eur. J. Immun. 5: 759-766.

ERB, P. and FEldmanN, M. (1975b) The role of macrophages in the generation of T-helper cells. II. The genetic control of the macrophage-T cell interaction for helper cell induction with soluble antigens. $J$. exp. Med. 142: 460-472.

ERB, P., FELdMANN, M. and HoGg, N. (1976) The role of macrophages in the generation of T-helper cells. IV. Nature of genetically related factor derived from macrophages incubated with soluble antigens. Eur. $J$. Immun. 6: 365-372.

Esteroff, T., Galinaud, P., Dormont, J., Wallon, C. and Tchernia, G. (1976) The xenogeneic effect-evidence for coparticipation of human monocytes and $T$ lymphocytes in the restoration of nude mouse in vitro response to sheep red blood cells. Eur. J. Immun. 6: 683-687.

Evans, R. and AleXander, P. (1972) Role of macrophages in tumor immunity. I. Cooperation between macrophages and lymphoid cells in syngeneic tumor immunity. Immunology 23: 615-626.

EvaNs, R. and GRANT, C. K. (1972) Role of macrophages in tumor immunity. III. Cooperation between macrophages and lymphoid factors in an in vitro allograft situation. Immunology 22: 667-675.

FAHEY, J. L., ScoOGIN, R., UTZ, J. and SzWED, C. (1963) Infection, antibody response and gamma globulin components in multiple myeloma and macroglobulinemia. Am. J. Med. 35: 698.

FANGER, M. W., HART, D. A., WElls, J. V. and NISONOFF, A. (1970) Enhancement by reducing agents of the transformation of human and rabbit peripheral lymphocytes. J. Immun. 105: 1043-1045.

FELDMANN, M. (1972a) Induction of immunity and tolerance in vitro by hapten protein conjugates. II. Carrier independence of the response to dinitrophenylated polymerized flagellin. Eur. J. Immun. 2: 130-137.

FeldmanN, M. (1972b) Cell interactions in the immune response in vitro. II. The requirement for macrophages in lymphoid cell collaboration. J. exp. Med. 135: 1049-1058.

FeldmanN, M. (1972c) Cell interactions in the immune response in vitro. V. Specific collaboration via complexes of antigen and thymus-derived cell immunoglobulin. J. exp. Med. 136: 737-760.

FeldmanN, M. and BASTEN, A. (1972) Cell interactions in the immune response in vitro. IV. Comparison of the effects of antigen-specific and allogeneic thymus-derived cell factors. $J$. exp. Med. 136: 722-736.

Feldmann, M., Greaves, M. F., Parker, D. C. and Rittenberg, M. B. (1974) Direct triggering of B lymphocytes by insolubilized antigen. Eur. J. Immun. 4: 591-597.

Feldmann, M. and PALMER, J. (1971) The requirement for macrophages in the secondary immune response to antigens of small and large size in vitro. Immunology 21: 685-699.

Fernbach, B. R., KiRCHNER, H. and Herberman, R. B. (1976a) Inhibition of the mixed lymphocyte culture by peritoneal exudate cells. Cell. Immun. 22: 399-403.

Fernbach, B. R., Kirchner, H., Bonnard, G. D. and Herberman, R. B. (1976b) Suppression of mixed lymphocyte responses in mice bearing primary tumors induced by murine sarcoma virus. Transplantation 21: 381-386.

Folch, H. and WaKSman, B. H. (1974) The spleen suppressor cell. II. Suppression of the mixed lymphocyte reaction by thymus-dependent adherent cells. J. Immun. 113: 140-144. 
Fox, T. O., Sheppard, J. R. and Burger, M. M. (1971) Cyclic membrane changes in animal cells: Transformed cells permanently display a surface architecture detected in normal cells only during mitosis. Proc. natn. Acad. Sci. USA 68: 244-247.

FRANZL, R. E. and MCMASTER, P. D. (1968) The primary immune response in mice. I. The enhancement and suppression of hemolysin production by a bacterial endotoxin. J. exp. Med. 127: 1087-1107.

Fujimoto, S., Greene, M. L. and Sehon, A. H. (1976a) Regulation of the immune response to tumor antigens. I. Immunosuppressor cells in tumor-bearing hosts. J. Immun. 116: 791-799.

Fujimoto, S., Greene, M. L. and Sehon, A. H. (1976b) Regulation of the immune response to tumor antigens. II. The nature of immunosuppressor cells in tumor-bearing hosts. J. Immun. 116: 800-806.

GADEBUSCH, H. H. (1972) Mechanisms of native and acquired resistance to infection with Cryptococcus neoformans. In: Macrophages and Cellular Immunity pp. 3-11, LASKIN, A. I. and Lechevalier, H. (eds.). CRC Press, Cleveland.

Gardner, R. J. and Preston, F. W. (1962) Prolonged skin homograft survival in advanced cancer and cirrhosis and the liver. Surgery Gynec. Obstet. 115: 399-402.

GERSHON, R. K. (1974) T cell control of antibody production. In: Contemporary Topics in Immunobiology Vol. 3, pp. 1-40, Cooper, M. D. and Warner, N. L. (eds.). Plenum Press, New York, London.

Gery, I., Gershon, R. K. and Waksman, B. H. (1972) Potentiation of the T-lymphocyte response to mitogens. I. The responding cell. J. exp. Med. 136: 128-142.

Glaser, M., Kirchner, H. and Herberman, R. B. (1975) Inhibition of in vitro lymphoproliferative responses to tumor associated antigens by suppressor cells from rats bearing progressively growing Gross leukemia virus-induced tumors. Int. J. Cancer 16: 384-393.

Glaser, M., Kirchner, H., Holden, H. T. and Herberman, R. B. (1976) Inhibition of cell-mediated cytotoxicity against tumor-associated antigens by suppressor cells from tumor-bearing mice. J. natn. Cancer Inst. 56: 865-867.

GoldsteIN, P. and Blomgren, H. (1973) Further evidence for autonomy of T cells mediating specific in vitro cytotoxicity: Efficiency of very small amounts of highly purified T cells. Cell. Immun. 9: 127-141.

GORCZYNSKI, R. M. (1976) Control of the immune response: role of macrophages in regulation of antibodyand cell-mediated immune responses. Scand. J. Immun. 5: 1031-1047.

GREINEDER, D. and ROSENTHAL, A. (1975a) The requirement for macrophage-lymphocyte interaction in T-lymphocyte proliferation induced by generation of aldehydes on cell membranes. J. Immun. 115: 932-938.

Greineder, D. K. and Rosenthal, A. S. (1975b) Macrophage activation of allogeneic lymphocyte proliferation in the guinea pig mixed leukocyte culture. J. Immun. 114: 1541-1547.

HaLPERN, B. N. (ed.) (1975) Corynebacterium parvum: Application in Experimental and Clinical Oncology. Plenum Press, New York.

Halpern, B. N., Prevot, A. R., Biozzi, G., Stiffel, C., Mouton, D., Morard, J. C., Bouthillier, Y. and DECREUSEFOND, C. (1963) Stimulation de l'activité phagocytaire du système réticuloendothélial provoquée par Corynebacterium parvum. J. Reticuloendothel. Soc. 1: 77-85.

Hammerling, G. J. (1976) Tissue distribution of la antigens and their expression on lymphocyte subpopulations. Transplant Rev. 30: 64-82.

HARDY, B., Glorerson, A. and DANON, D. (1973) Ontogenic development of the reactivity of macrophages to antigenic stimulation. Cell. Immun. 9: 282-288.

Heber-Katz, E. and Wilson, D. B. (1975) Collaboration of allogeneic T and B lymphocytes in the primary antibody response to sheep erythrocytes in vitro. J. exp. Med. 142: 928-935

Herberman, R. B., Aoki, T., Nunn, M., Lavrin, D. H., Soares, N., Gazdar, A., Holden, H. and Chang, K. S. S. (1974) Specificity of ${ }^{51} \mathrm{Cr}$-release cytotoxicity by lymphocytes immune to murine sarcoma virus. J. natn. Cancer Inst. 53: 1103-1111.

Herberman, R. B., NunN, M. E., Holden, H. T. and Lavrin, D. H. (1975) Natural cytotoxic reactivity of mouse lymphoid cells against syngeneic and allogeneic tumor. II. Characterization of effector cells. Int. J. Cancer 16: 230-239.

Herberman, R. B., Nunn, M. E., Holden, H. T., Staal, S. and Djeu, J. Y. (1977) Augmentation of natural cytotoxic reactivity of mouse lymphoid cells against syngeneic and allogeneic target cells. Int. J. Cancer 19: 555-564.

Hersh, E. M., Gutterman, J. U. and Mavligit, G. (1973) Immunological deficiency cancer. In: Immunotherapy of Cancer in Man pp. 3-18. Charles C. Thomas, Springfield, IL.

Herzenberg, L. A., Okumura, K., Cantor H., Sato, V. L., Shen, F., Boyse, E. A. and Herzenberg, L. A. (1976) T-cell regulation of antibody responses: Demonstration of allotype-specific helper $T$ cells and their specific removal by suppressor T cells. J. exp. Med. 144: 330-344.

HisBs, J. B. (1973) Macrophage nonimmunologic recognition: target cell factors related to contact inhibition. Science 180: 868-870.

Hibss, J. B. (1974) Heterocytolysis by macrophages activated by Bacillus Calmette-Guerin: Lysosome exocytosis into tumor cells. Science 184: 468-471.

Hibis, J. B., LAmberT, L. H. and Remington, J. S. (1972) Possible role of macrophage mediated nonspecific cytotoxicity in tumor resistance. Nature New Biol. 235: 48-50.

Hoffman, M. (1970) Peritoneal macrophages in the immune response to SRBC in vitro. Immunology 18: 791-797.

Hoffman, M. K., Green, S., Old, L. J. and Oettgen, H. F. (1976a) Serum containing endotoxin-induced tumour necrosis factor substitutes for helper T cells. Nature 263: 416-417.

Hoffman, M. K., Hammerling, U., Simon, M. and Oetrgen, H. F. (1976b) Macrophage requirements of CR - and CR + B lymphocytes for antibody production in vitro. J. Immun. 116: 1447-1451.

Holden, H. T., Haskill, J. S., Kirchner, and Herberman, R. B. (1976) Two functionally distinct anti-tumor effector cells isolated from primary murine sarcoma virus-induced tumors. $J$. Immun. 117: $440-446$.

Holtermann, O. A., Klein, E. and Casale, G. P. (1973) Selective cytotoxicity of peritoneal leucocytes for neoplastic celils. Cell. Immun. 9: 339-352. 
Holtermann, O. A., Lisafeld, B. A., Klein, E. and KlostergaArd, J. (1975) Cytocidal and cytostatic effects of activated peritoneal leukocytes. Nature 257: 228-229.

Horton, J. E., Oppenheim J. J., Mergenhagen, S. E. and Raisz, L. G. (1974) Macrophage-lymphocyte synergy in the production of osteoclast activating factor. J. Immun. 113: 1278-1287.

Howard, J. G., Biozzi, G., Stiffel, C., Mouton, D. and Liacopoulos, P. (1967) An analysis of the inhibitory effect of Corynebacterium parvum on graft-versus-host disease. Transplantation 5: 15101524.

Jerne, N. K. and Nordin, A. A. (1963) Plaque formation in agar by single antibody-producing cells. Science 140: 405 .

JONES, A. L. (1971) Effect of column purification on response of lymphocytes in mixed leukocyte cultures (MLC) and to blastogenic media derived from MLCS. Clin. exp. Immun. 8: 927-939.

Julius, M. H., Simpson, E. and Herzenberg, L. A. (1973) A rapid method of the isolation of functional thymus-derived lymphocytes. Eur. J. Immun. 3: 345-347.

Kagnoff, M. F., Billings, P. and CoHn, M. (1974) Functional characteristics of Peyer's patch lymphoid cells. II. Lipopolysaccharide is thymus dependent. J. exp. Med. 139: 407-413.

KapP, J., Pierce, W. and Benacerraf, B. (1973) Genetic control of immune responses in vitro. II. Cellular requirements for the development of primary plaque-forming cell responses to the random terpolymer L-glutamic acid ${ }^{60}-\mathrm{L}$-alanine ${ }^{30}-\mathrm{L}-$ tyrosine $^{10}$ (GAT) by mouse spleen celis in vitro. J. exp. Med. 138: $1121-1132$.

KATZ, D. H. and BENACERRAF, B. (1972) The regulatory influence of activated T-cells on B-cells responses to antigens. Adv. Immun. 15: 2-85.

Katz, D. H., ChIorazzI, N., McDonald, J. and KaTZ, L. R. (1976) Cell interactions between histoincompatible $\mathrm{T}$ and $\mathrm{B}$ lymphocytes. IX. The failure of histocompatible cells is not due to suppression and cannot be circumvented by carrier-priming $\mathrm{T}$ cells with allogeneic macrophages. J. Immun. 117: 1853-1859.

KATZ, D., HAMAOKA, T. and BENACERRAF, B. (1973a) Cell interactions between histoincompatible T and B lymphocytes. II. Failure of physiologic cooperative interactions between $\mathrm{T}$ and $\mathrm{B}$ lymphocytes from allogeneic donor strains in humoral response to hapten-protein conjugates. J. exp. Med. 137: 1405-1418.

Katz, D. H., Hamaoka, T., Dorf, M. E. and Benacerraf, B. (1973b) Cell interactions between histoincompatible $\mathrm{T}$ and $\mathrm{B}$ lymphocytes. The $\mathrm{H}-2$ gene complex determines successful physiologic lymphocyte interactions. Proc. natn. Acad. Sci. USA 70: 2624-2628.

KaTZ, D. H. and Unanue, E. R. (1973) Critical role of determinant presentation in the induction of specific responses in immuno-competent lymphocytes. J. exp. Med. 137: 967-990.

KELlER, R. (1974a) Modulation of cell proliferation by macrophages: A possible function apart from cytotoxic tumour rejection. Br. J. Cancer 30: 401-415.

KELLER, R. (1974b) Mechanisms by which activated normal macrophages destroy syngeneic rat tumor cells in vitro. Immunology 27: 285-298.

KELLER, R. (1975) Major changes in lymphocyte proliferation evoked by activated macrophages. Cell. Immun. 17: 542-551.

KELLER, R. (1976) Susceptibility of normal and transformed cell lines to cytostatic and cytocidal effects exerted by macrophages. J. natn. Cancer Inst. 56: 369-374.

Keller, R., KeIST, R. and IVATT, R. J. (1974) Functional and biochemical parameters of activation related to macrophage cytostatic effects on tumor cells. Int. J. Cancer 14: 675-683.

Kirchner, H., Herberman, R. B., Glaser, M. and Lavrin, D. H. (1974b) Suppression of in vitro lymphocyte stimulation in mice bearing primary Moloney sarcoma virus-induced tumors. Cell. Immun. 13: $32-40$.

Kirchner, H., Chused, T. M., Herberman, R. B., Holden, H. T. and Lavrin, D. H. (1974b) Evidence of suppressor cell activity in spleens of mice bearing primary tumors induced by Moloney sarcoma virus. J. exp. Med. 139: 1473-1487.

Kirchner, H., Fernbach, B. R. and Herberman, R. B. (1976) Macrophages suppressing T and B cell mitogen responses and the mixed leukocyte reaction. In: Mitogens in Immunology pp. 495-507, Oppenheim, J. J. and Rosenstreich, D. L. (eds.). Academic Press, New York.

Kirchner, H., Muchmore, A. V., Chused, T. M., Holden, H. T. and Herberman, R. B. (1975a) Inhibition of proliferation of lymphoma cells and $\mathrm{T}$ lymphocytes by suppressor cell from spleens of tumor-bearing mice. J. Immun. 144: 206-210.

Kirchner, H., Glaser, M. and Herberman, R. B. (1975b) Suppression of cell-mediated tumour immunity by Corynebacterium parvum. Nature 257: 396-398.

KirChNER, H., Holden H. T. and HeRberman, R. B. (1975c) Splenic suppressor macrophages induced in mice by injection of Corynebacterium parvum. J. Immun. 115: 1212-1216.

KLAUS, G. G. B. (1974) Generation of thymus-derived helper cells by macrophage-associated antigen. Cell. Immun. 10: 483-488.

Klaus, G. G. B., Howard, J. G. and Feldmann, M. (1976) Mechanisms of B cell tolerance. Br. med. J. 32: $141-146$.

Kolb, J-P., Arrian, S. and Zolla-Pazner, S. (1977) Suppression of the humoral immune response by plasmacytomas: mediation by adherent mononuclear cells. J. Immun. 118: 702-709.

Krakauer, R. S., Strober, W. and Waldmann, T. A. (1976) Hypogammaglobulinemia in experimental myeloma: the role of suppressor mononuclear phagocytes. Clin. Res. 24: 337a

Kunz, H. W., GILL, T. J., III and Borland, B. (1974) The genetic linkage of the immune response to poly (Glu52Lys33Tyr15) to the major histocompatibility locus in inbred rate. J. Immunogenetics 1: 277-287.

Lake, W. W., Bice, D., Schwartz, J. and Salvaggio, J. (1971) Suppression of in vitro antigen-induced lymphocyte transformation by carrageenan, a macrophage-toxic agent. J. Immun. 107: 1741-1745.

Lamb, D., Pilney, F., Kelly, W. D. and Good, R. A. (1962) A comparative study of the incidence of anergy in patients with carcinoma, leukemia, Hodgkin's disease and other lymphomas. J. Immun. 89: $555-558$.

Landolfo, S., Herberman, R. B. and Holden, H. T. (1977) Stimulation of mouse migration inhibitory 
factor (MIF) production from MSV-immune lymphocytes by soluble tumor associated antigen: requirement for histocompatible macrophages. J. Immun. 118: 1244-1248.

Landolfo, S., Herberman, R. B. and Holden, H. T. (1978) Cellular immunity to murine sarcoma virus-induced tumors as measured by macrophage migration inhibition assorp. J. natn. Cancer Inst. (in press).

Lapp, W. S. and Moller, G. (1969) Prolonged survival of H-2 incompatible skin allografts on $F_{1}$ animals treated with parental lymphoid cells. Immunology 17: 339-334.

LEE, A. K. Y., RowLEY, M. and MACKAY, I. R. (1970) Antibody-producing capacity in human cancer. Br. J. Cancer 24; 454-463.

Lee, K. C., Shiozawa, C., Shaw, A. and Diener, E. (1976) Requirement for accessory cells in the antibody response to T cell-independent antigens in vitro. Eur. J. Immun. 6: 63-68.

LeIBovich, S. J. and Ross, R. (1975) Macrophages and anti-macrophage serum. In: Mononuclear Phagocytes in Immunity, Infection and Pathology pp. 151-160, VAN FURTH, R. (ed.). Blackwell Scientific Publications, London.

Lemke, H., Coutinho, A., Opitz, H. and Gronowicz, E. (1975) Macrophages suppress direct B cell activation by lipopolysaccharide. Scand. J. Immun. 4: 707-720.

LIPSKY, P. and ROSENTHAL, A. (1973) Macrophage-lymphocyte interaction. I. Characteristics of the antigen-independent binding of guinea pig thymocytes and lymphocytes to syngeneic macrophages. $J$. exp. Med. 138: 900-921.

Lipsky, P. E. and Rosenthal, A. S. (1976) The induction and regulation of guinea pig B-lymphocyte proliferation in vitro. J. Immun. 117: 1594-1602.

LOGAN, J. (1956) The delayed type of allergic reaction in cancer altered response to tuberculin and mumps virus. N. Z. med. J. 55: 408-410.

Lohrmann, P. H., Novikovs, L. and Graw, R. G. (1974) Cellular interactions in the proliferative response of human $\mathrm{T}$ and $\mathrm{B}$ lymphocytes to phytomitogens and allogeneic lymphocytes. $J$. exp. Med. 139: $1553-1567$.

LY, I. A. and Mishell, R. I. (1974) Separation of mouse spleen cells by passage through columns of Sephadex G-10. J. Immun. Meth. 5: 239-247.

MCGREGOR, D. D. and KoSiER, F. T. (1971) The mediator of cellular immunity. IV. Cooperation between lymphocytes and mononuclear phagocytes. Cell. Immun. 2: 317-325.

MCGREGOR, D. D. and LOGIE, P. S. (1975) Macrophocyte-lymphocyte interactions in infection immunity. In: Mononuclear Phagocytes in Immunity, Infection, and Pathology pp. 631-661, FURTH, R. V. (ed.). Blackwell Scientific Publications, Oxford, London.

MCINTYRe, J. and PIERCE, C. (1973) Immune responses in vitro. IX. Role of cell clusters. J. Immun. 111: $1562-1537$.

Miller, J. F. A. P., Vadas, M. A., Whitelaw, A. and Gamble, J. (1967a) Role of major histocompatibility complex gene products in delayed-type hypersensitivity. Proc. natn. acad. Sci. USA. 73: 2486-2490.

Miller, J. F. A. P., Vadas, M. A., Whitelaw, A. and Gamble, J. (1976b) H-2 linked Ir gene regulation of delayed-type hypersensitivity in mice. In: The Role of Products of the Histocompatibility Gene Complex in Immune Responses pp. 403-415, KATZ, D. and BENACERRAF, B. (eds.). Academic Press, New York.

Mishell, R. I. and Dutton, R. W. (1966) Immunization of normal mouse spleen cell suspensions in vitro. Science 153: 1004-1005.

Mitchell, M. S., Kirkpatrick, D., MokyR, M. B. and Gery, I. (1973) On the mode of action of BCG. Nature New Biol. 243: 216-217.

Mitchison, N. A. (1969) The immunogenic capacity of antigen taken up by peritoneal exudate cells. Immunology 16: 1-14.

Mokyr, M. B. and Mitchell, M. S. (1975) Activation of lymphoid cells by BCG in vitro. Cell. Immun. 15: 264-273.

MOLLER, G. (1971a) Induction of antigenic competition with thymus-dependent antigens: Effect on DNA synthesis in spleen cells. J. Immun. 106: 1566-1571.

MöLlER, G. (1971b) Suppressive effect of graft versus host reaction on the immune response to heterologous red cells. Immunology 20: 597-609.

Moller, G., LemKe, H. and OPITZ, H.-G. (1976) The role of adherent cells in the immune response. Scand. $J$. Immun. 5: 2969-280.

Mosier, D. E. (1967) A requirement for two cell types for antibody formation in vitro. Science 158: 1573-1575.

MosIER, D. E. (1968) Cell interactions in the primary immune response in vitro: a requirement for specific cell clusters. J. Immun. 129: 351-362.

Mosier, D. E., Johnson, B. M., Paul, W. E. and McMaster, P. R. B. (1974) Cellular requirements for the primary in vitro antibody response to DNP-Ficoll. J. exp. Med. 139: 1354-1360.

Mozes, E. and Shearer, G. M. (1971) Contribution of bone marrow cells and lack of expression of thymocytes in genetic controls of immune responses for two immunopotent regions with Poly-(Phe. Glu) Poly Pro-Poly-Lys in inbred mouse strains. J. exp. Med. 134: 141-161.

Murphy, D. B., Herzenberg, L. A., OKumura, K., Herzenberg, L. A. and McDevitT, H. O. (1976) A new subregion $(I-J)$ marked by a locus $(\mathrm{Ja}-4)$ controlling surface. Determinants of suppressor T lymphocytes. J. exp. Med. 144: 699-712.

Nathan, C. F., Hill, V. M. and Terry, W. T. (1976) Isolation of a subpopulation of adherent peritoneal cells with anti-tumor activity. Nature 260: 146-148.

Nathan, C. F., KaRnovsky, M. L. and David, J. R. (1971) Alterations of macrophage functions by mediators from lymphocytes. J. exp. Med. 133: 1356-1376.

Nathan, C. F., Remold, H. G. and David, J. R. (1973) Characterization of a lymphocyte factor which alters macrophage functions. J. exp. Med. 137: 275-290.

NiedERHuber, J. E. and SHREFFLeR, D. C. (1977) Anti-Ia serum blocking of macrophage function in the in vitro humoral response. Transplant. Proc. 9: 875-879. 
NITULESCU, G. and FöRSTER, O. (1976) Antigenic differences between rat alveolar and peritoneal macrophages. Adv. exp. Med. Biol. 73A: 53-58.

OeHLER, J. R. and HERBERMAN, R. B. (1977) Interaction of T cells with allogeneic macrophages in mixed leukocyte cultures in rats. $J$. Immun. 19: 1785-1789.

Oehler, J. R., Campbell, D. A. and Herberman, R. B. (1977a) In vitro inhibition of lymphoproliferative responses to tumor associated antigens and of lymphoma cell proliferation by rat splenic macrophages. Cell. Immun. 28: 355-370.

Oehler, J. R., Herberman, R. B., Campbell, D. A. and DJeu, J. Y. (1977b) Inhibition of rat mixed lymphocyte cultures by suppressor macrophages. Cell. Immun. 29: 238-250.

OEHLER, J. R., CAMPBELl, D. A. and HERBERMAN, R. B. (1977c) Adherent suppressor cells in normal rat spleen. Proceedings of the Eleventh Leukocyte Culture Conference pp. 797-799, Academic Press, New York.

$\mathrm{OHISHI}, \mathrm{M}$. and ONOUE, K. (1975) Functional activation of immune lymphocytes by antigenic stimulation in cell-mediated immunity. I. Requirement for macrophages in antigen-induced MIF production by guinea pig immune lymphocytes in vitro. Cell. Immun. 18: 220-232.

OHISHI, M. and ONOUE, K. (1976) Functional activation of immune lymphocytes by antigenic stimulation in cell-mediated immunity. II. Analysis of the macrophage-replacing activity of the LPS-stimulated macrophage culture supernatant in the antigenic activation of purified immune lymphocytes. Cell. Immun. 26: 295-307.

Opitz, H.-G., Niethammer, D., Jackson, R. C., Lemke, H., Huget, R. and Flad, H. D. (1975a) Biochemical characterization of a factor released by macrophages. Cell. Immun. 18: 70-75.

Opitz, H. G., Neithammer, D., Lemke, H., Flad, H. D. and Huget, R. (1975b) Inhibition of ${ }^{3}$ H-thymidine incorporation of lymphocytes by a soluble factor from macrophages. Cell. Immun. 16: 379-388.

Opitz, H. G., Opitz, U., Lemke, Huget, R. and Flad, H. D. (1976) Polyclonal stimulation of lymphocytes by macrophages. Eur. J. Immun. 6: 457-461.

Oppenheim, J., LeVEnTHAL, B. and HeRSH, E. (1968) The transformation of column-purified lymphocytes with nonspecific and specific antigenic stimuli. J. Immun. 101: 262-270.

OPPENHEIM, J. J. and ROSENSTREICH, D. L. (1976) Signals regulating in vitro activation of lymphocytes. Prog. Allergy 20: 65-159.

OPPENHEIM, J. J. and SEEGER, R. C. (1976) The role of macrophages in the induction of cell-mediated immunity in vitro. In: Immunobiology of the Macrophage pp. 111-130, NELSON, D. S. (ed.). Academic Press, New York.

PARrot, D. M. V. and DeSousa, M. (1971) Thymus-dependent and thymus-independent populations: Origin, migratory patterns and lifespan. Clin. exp. Immun. 8: 663-684.

Paul, W. E. and BenaCerraf, B. (1974) Antigen recognition. In: Mechanisms of Cell-Mediated Immunity pp. 61-97, McCluskey, R. T. and CoHEN, S. (eds.). John Wiley, New York.

Paul, W. E., Shevach, E. M., Thomas, D. W., Pickeral, S. F. and Rosenthal, A. S. (1977) Genetic restriction in T-lymphocyte activation by antigen-pulsed peritoneal exudate cells. Cold Spring Harb. Symp. quant. Biol. 41: 571-578.

PeAvy, D. L. and PIERce, C. W. (1974) Cell-mediated immune response in vitro. I. Suppression of the generation of cytotoxic lymphocytes by Concanavalin A and Concanavalin A-activated spleen cells. $J$. exp. Med. 140: 356-369.

Peavy, D. L. and PIERCE, C. W. (1975) cell-mediated immune response in vitro. III. Elimination of specific cytotoxic lymphocyte responses by ${ }^{3} \mathrm{H}$-thymidine suicide. J. Immun. 115: 1521-1524.

PERKINS, E. H. and MAKINODAN, T. (1965) The suppressive role of mouse peritoneal phagocytes in agglutinin response. J. Immun. 94: 765-777.

PIERCE, C. W. (1969) Immune responses in vitro. I. Cellular requirements for the immune response by non-primed and primed spleen cells in vitro. J. exp. Med. 130: 345-350.

PIERCE, C. W. (1973) Immune responses in vitro. IV. Cell interactions in the development of primary IgM, and Ig A plaque-forming cell responses in vitro. Cell. Immun. 9: 453-464.

PIERCE, C. W. and KAPP, J. A. (1976) The role of macrophages in antibody responses in vitro. In: Immunobiology of the Macrophage pp. 1-33, NeLson, D. S. (ed.). Academic Press, New York.

Pierce, C., KapP, J. and BenaCerRaF, B. (1976) Regulation by the $\mathrm{H}-2$ gene complex of macrophagelymphoid cell interactions in secondary antibody responses in vitro. J. exp. Med. 144: 371-381.

Pierce, C., KAPP, J., WoOD, D. and BenaCerRaF, B. (1974) Immune responses in vitro. X. Functions of macrophages. J. Immun. 112: 1181-1189.

Piessens, W. F., Churchill, W. H. and David, J. R. (1975) Macrophages activated in vitro with lymphocyte mediators kill neoplastic büt not normal cells. J. Immun. 114: 293-299.

PIKE, B. L. and NosSal, G. J. V. (1976) Requirement for persistent extracellular antigen in cultures of antigen-binding B lymphocytes. J. exp. Med. 144: 568-572.

Plata, F., Cerottini, J. C. and Brunner, K. T. (1975) Primary and secondary in vitro generation of cytolytic T lymphocytes in the murine sarcoma virus system. Eur. J. Immun. 5: 227-233.

Pope, B. L., WhitNEy, R. B., LEVy, J. G. and KILbURN, D. G. (1976) Suppressor cells in the spleens of tumor-bearing mice: Enrichment by centrifugation on Hypaque-Ficoll and characterization of the suppressor population. J. Immun. 116: 1342-1346.

Poplack, D. G., Bonnard, G. D., Holiman, B. J. and Blaese, R. M. (1976) Monocyte-medicated antibody-dependent cellular toxicity: a clinical test of monocyte function. Blood 48: 809-816.

Postlethwaite, A. E., Snyderman, R. and Kand, A. H. (1976) The chemotactic attraction of human fibroblasts to a lymphocyte-derived factor. J. exp. Med. 144: 1188-1203.

PrÉVOT, A. R. (1975) Bacteriological aspect of anaerobic Corynebacteria in relation to RES stimulation. In: Corynebacterium Parvum; Applications in Experimental and Clinical Oncology pp. 3-10, HALPERN, B. (ed.). Plenum Press, New York.

Pross, H. F. and EIDINGER, D. (1974) Antigenic competition: a review of nonspecific antigen-induced suppression. Adv. Immun. 18: 133-168.

Remington, J. S., Krahenbuhl, J. L. and HibBs, J. B., JR. (1975) A role for the macrophage in resistance to tumor development and tumor destruction. In: Mononuclear Phagocytes in Immunity, Infection and 
Pathology pp. 869-893, Van FurTh, R. (ed.). Blackwell Scientific Publications, Oxford.

Renaud, M. (1926) La cuti réaction à la tuberculine chez les cancereaux. Bull. Mém. Soc. Méd. Paris 50: $1441-1442$.

RHODES, J. (1975) Macrophage heterogeneity in receptor activity: the activation of macrophage Fc receptor function in vivo and in vitro. J. Immun. 114: 976-981.

RICH, R. R. and PIERCE, C. W. (1974) Biological expressions of lymphocyte activation. J. Immun. 112: $1360-1368$.

RODE, H. N. and GoRdon, J. (1974) Macrophages in the mixed leukocyte culture reaction (MLC). Cell. Immun. 13: 87-94.

Rosenstreich, D. L. and Oppenheim, J. J. (1976) The role of macrophages in the activation of T and B lymphocytes in vitro. In: Immunobiology of the Macrophage pp. 162-197, NELSON, D. S. (ed.) Academic Press, London.

Rosenthal, A. and Shevach, E. (1973) Function of macrophages in antigen recognition by guinea pig $T$ lymphocytes. I. Requirement for histocompatible macrophages and lymphocytes. J. Immun. 138 1194-1212.

Sawicki, J. E. and Catanzaro, P. J. (1975) Selective macrophage cytotoxicity of carrageenan in vivo. Int Archs Allergy appl. Immun. 49: 709-714.

SChRADER, J. W. (1973) Mechanism of activation of the bone marrow-derived lymphocyte. J. exp. Med. 138: $1466-1480$.

SChrader, J. W. and Feldmann, M. (1973) The mechanism of antigenic competition. I. The macrophage as a site of a reversible block of T-B lymphocyte collaboration. Eur. J. Immun. 3: 711-717.

SCHWARTZ, H. J. and LeSKowITZ, S. (1969) The effect of carrageenan on delayed hypersensitivity reactions. $J$ Immun. 103: 87-91.

ScotT, M. T. (1972) Biological effects of the adjuvant Corynebacterium parvum. I. Inhibition of PHA, mixed lymphocyte and GVH reactivity. Cell. Immun. 5: 459-468.

SCOTT, M. T. (1972) Biological effects of the adjuvant Corynebacterium parvum. II. Evidence for macrophageT-cell interaction. Cell. Immun. 5: 469-479.

ScoT, M. T. (1974) Depression of delayed-type hypersensitivity by Corynebacterium parvum: mandatory role of the spleen. Cell. Immun. 13: 251-263.

SEeger, R. and OPPENHIEM, J. (1970) Synergistic interaction of macrophages and lymphocytes in antigeninduced transformation of lymphocytes. J. exp. Med. 132: 44-65.

ShevaCH, E. M. (1976) The function of macrophages in antigen recognition by guinea pig T-lymphocytes. III. Genetic analysis of the antigens mediating macrophage-T lymphocyte interaction. J. Immun. 116 $1482-1489$

Shevach, E. M. and Rosenthal, A. S. (1973) The function of macrophages in antigen recognition by guinea pig T-lymphocytes. II. Role of the macrophage in the regulation of genetic control of the immune response. J. exp. Med. 138: 1213-1229.

Shilo, M. (1959) Nonspecific resistance to infections. Ann. Rev. Microbiol. 13: 255-278.

ShINITZKY, M. and INBAR, M. (1974) Difference in microviscosity induced by different cholesterol levels in the surface membrane lipid layer of normal lymphocytes and malignant lymphoma cells. J. molec. Biol. 85: $603-615$.

SHORTMAN, K. (1968) The separation of different cell classes from lymphoid organs. II. The purification and analysis of lymphocyte populations by equilibrium density gradient centrifugation. Aust. J. exp. Biol. med. Sci. 46: 375-396.

Shortman, K.. Diener, E., Russel, P. and Armstrong, W. D. (1970) The role of nonlymphoid accessory cells in the immune response to different antigens. J. exp. Med. 131: 461-482.

Shortman, K. and PALmer, J. (1971) The requirement for macrophages in the in vitro immune response Cell. Immun. 2: 399-410.

Shreffler, D. C. and DAvid, C. S. (1975) The H-2 major histocompatibility complex and the I immune response region: genetic variation, function, and organization. Adv. Immunol. 20: 125-190.

SJöBERG, O. (1971) Antigenic competition in vitro of spleen cells subjected to a graft-versus-host reaction Immunology 21: 351-361.

SJÖBERG, O. (1972) Effect of allogeneic cell interaction on the primary immune response in vitro. Clin. exp. Immun 12: 365-375.

SJöberG, O., ANDERSON, J. and Moller, G. (1972) Requirement for adherent cells in the primary and secondary immune response in vitro. Eur. J. Immun.

SuöbERG, O. and BRITTON, S. (1972) Antigenic competition in vitro between heterologous erythrocytes. Eur. J. Immun. 2: 282-288.

SMITH, R. T. (1972) Possibilities and problems of immunologic intervention in cancer. New Engl. J. Med. 287: $439-450$.

SMITH, R. T. and KonDA. S. (1973) The stimulatory effects of bearing primary methylcholanthrene-induced tumors upon the murine lymphoreticular system. Int. J. Cancer 12: 577-588.

SMITH, S. E. and ScoTT, M. T. (1972) Biological effects of Corynebacterium paruum. III. Amplification of resistance and impairment of active immunity to murine tumours. Br. J. Cancer 26: 361-367.

Solowey, A. C. and RAPAPORT, F. T. (1965) Immunologic responses in cancer patients. Surgery Gynec. Obstet. 121: 756-760.

Southam, C. M., Brunschwig, A. and Dixon, Q. (1962) In: Biological Interactions in Normal and Neoplastic Growth p. 723, BREnNAN, M. J. and Simpson, W. L. (eds.). Little and Brown, Boston.

Spitznagel, J. K. and Allison, A. C. (1970) Mode of action of adjuvants: retinol and other lysosomelabilizing agents as adjuvants. J. Immun. 104: 119-127.

TADA, N., ITAKuRA K., and AIZAwa, M. (1976) Immune response gene (Ir-SRBC) exerts its effects via macrophages in inbred rats. $J$. Immunogenetics 3:49-60.

TADA, T. and TANIGUCHI, M. (1976) Characterization of the antigen-specific suppressive $T$ cell factor with special reference to the expression of region genes. In: The Role of Products of the Histocompatibility Gene complex in Immune Responses pp. 513-541, KATZ, D. H. and BENACERRAF, B. (eds.). Academic Press, New York. 
Tadakuma, T., Kuhner, A. L., Rich, R. R., David, J. R. and Pierce, C. W. (1976a) Biological expressions of lymphocyte activation. V. Characterization of a soluble immune response suppressor (SIRS) produced by Concanavalin A-activated spleen cells. J. Immun. 117: 323-330.

Tadakuma, T. and PIERCE, C. W. (1976b) Site of action of a soluble immune response suppressor (SIRS) produced by Concanavalin A-activated spleen cells. J. Immun. 117: 967-972.

TERRITO, M. and Cline, M. J. (1976) Macrophages and their disorders in man. In: Immunobiology of the Macrophage pp. 593-616, Nelson, D. S. (ed). Academic Press, New York.

Thomas, D. W., Roberts, W. K. and Talmage, D. W. (1975) Regulation of the immune response: production of a soluble suppressor by immune spleen cells in vitro. J. Immun. 114: 1616-1622.

Thomas, D. W. and Shevach, E. (1976) Nature of the antigenic complex recognized by T-lymphocytes. I. Analysis with an in vitro primary response to soluble protein antigens. J. exp. Med. 144: 1263-1273.

Thomas, D. W. and Shevach, E. M. (1977a) Nature of the antigenic complex recognized by Tlymphocytes. II. T cell activation by direct modification of macrophage histocompatibility antigens. $J$. exp. Med. 145: 907-915.

Thomas, D. W. and Shevach, E. M. (1977b) Nature of the antigenic complex recognized by Tlymphocytes. III. Specific sensitization by antigens associated with allogeneic macrophages. Proc. natn. Acad. Sci. USA 74: 2104-2110.

TURK, J. L. and WATERS, F. R. (1971) Immunological significance of changes in lymph nodes across the leprosy spectrum. Clin. exp. Immun. 8: 363-376.

Twomey, J. J., Laughter, A., Farrow, S. and Douglass, C. C. (1975) Hodgkin's disease. An immunodepleting and immunosuppressive disorder. I. clin. Invest. 56: 467-475.

UNANUE, E. R. (1969) The immune response of mice to keyhole limpet hemocyanin bound to macrophages. J. Immun. 102: 893-898.

UNANUE, E. R. (1972) The regulatory role of macrophages in antigen stimulation. Adv. Immun. 15: 95-157.

Unanue, E. R., Askonas, B. A. and Allison, A. (1969a) A role of macrophages in the stimulation of immune responses by adjuvants. J. Immun. 103: 71.

UnAnue, E. R., Cerottini, J.-C. and BEDRod, M. (1969b) The persistence of antigen on the surface of macrophages. Nature 222: 1193-1194.

VeIT, B. C. and FeldmanN, J. D. (1976a) Altered lymphocyte functions in rats bearing syngeneic Moloney sarcoma tumors. I. Mitogen responses, mixed lymphocyte reactions (MLR) and mixed lymphocytetumor reactions (MLTR). J. Immun. 117: 646-654.

VetT, B. C. and FeldmanN, J. D. (1975b) Altered lymphocyte functions in rats bearing syngeneic Moloney sarcoma tumors. II. Suppressor cells. J. Immun. 117: 655-660.

VIROLAINEN, M. LAHTI, A. and HÄYRY, P. (1972) Differentiation of macrophage antigen(s) in mouse bone marrow and buffy coat cultures. In: Experimental Medicine and Biology Vol. 15. Plenum Press, New York

VON BOEHMER, H., HUDSON, L. and SPRINT, J. (1975a) Collaboration of histoincompatible T and B lymphocytes using cells from tetraparental bone marrow chimeras. J. exp. Med. 142: 989-997.

von Boehmer, H., Sprent, J. and Nabholz, M. (1975b) Tolerance to histocompatibility determinants in tetraparental bone marrow chimeras. $J$. exp. med. 141: 322-334.

Wagner, H., Feldmann, M., Boyle, W. and Schrader, J. W. (1972) Cell-mediated immune response in vitro. III. The requirement for macrophages in cytotoxic reactions against cell-bound and subcellular alloantigens. J. exp. Med. 136: 331-343.

Wahl, S. M., Wilton, J. M., Rosenstreich, D. L. and Oppenheim, J. J. (1975) The role of macrophages in the production of lymphokines by $\mathrm{T}$ and B lymphocytes. J. Immun. 114: 1296-1301.

Waldman, S. R. and GotTlieb, A. A. (1973) Macrophage regulation of DNA synthesis in lymphoid cells: effects of a soluble factor from macrophages. Cell. Immun. 9: 142-146.

WALDRON, J., HoRn R. and Rosenthal, A. (1973) Antigen-induced proliferation of guinea pig lymphocytes in vitro. Obligatory role of macrophages in the recognition of antigen by immune T-lymphocytes. $J$. Immun. 111: 58-64.

WALDRON, J., HORN, R. and Rosenthal, A. (1974) Antigen-induced proliferation of guinea pig lymphocytes in vitro: functional aspects of antigen handling by macrophages. J. Immun. 112: 746-755.

WALKER, W. S. (1976a) Functional heterogeneity of macrophages. In: Immunobiology of the Macrophage Nelson, D. S. (ed.). Academic Press, New York.

WALKER, W. S. (1976b) Functional heterogeneity of macrophages in the induction and expression of acquired immunity. J. Reticuloendothelial Soc. 20: 57-65.

West, W. H., Cannon, G. B., Kay, H. D., Bonnard, G. B. and Herberman, R. B. (1977) Natural cytotoxic reactivity of human lymphocytes against a myeloid cell line: characterization of effector cells. $J$. Immun. 118: 355-361.

West, W. H., Sienknecht, C. W., Townes, A. S. and Herberman, R. B. (1976) Performance of a rosette assay between lymphocytes and sheep erythrocytes at elevated temperatures to study patients with cancer and other diseases. Clin. Immun. Immunopath. 5: 60-66.

Wolfe, S. A., TRACY, D. E. and HenNEY, C. S. (1976) Induction of 'natural killer' cells by BCG. Nature 262: $584-586$

WoOD, D. D. and CAmeron, P. M. (1975) Studies on the mechanism of stimulation of the humoral response of murine spleen cultures by culture fluids from human monocytes. J. Immun. 114: 1094-1100.

WooD, D. D. and GAUL, S. L. (1974) Enhancement of the humoral response of T cell-depleted murine spleens by a factor derived from human monocytes in vitro. J. Immun. 113: 925-933.

Woodruff, M. F. A., Ghaffar, A., Dunbar, N. and Whitehead, V. L. (1976) Effect of $C$. parvum on immunization with irradiated tumour cells. Br. J. Cancer 33: 491-495.

Woodruff, M. F. A., GhafFar, A. and Whitehead, V. L. (1976) Modification of the effect of C. parvum on macrophage activity and tumor growth by X-irradiation. Int. J. Cancer 17: 652-658.

YAM, L. T., LI, C. Y. and Crosby, W. H. (1971) Cytochemical identification of monocytes and granulocytes. Am. J. clin. Pathol. 55: 283-290.

Yoshinaga, M., Yoshinaga, A. and WaKSman, B. (1972) Regulation of lymphocyte responses in vitro. I. Regulatory effect of macrophages and thymus-dependent $(T)$ cells on the response of thymus-independent (B) lymphocytes to endotoxin. J. exp. Med. 136: 956-961. 